NISTIR 7178

\title{
Modeling Solid Sample Burning with FDS
}

Gregory T. Linteris, Lloyd Gewuerz, Kevin McGrattan, and Glenn Forney 
NISTIR 7178

\section{Modeling Solid Sample Burning with FDS}

Gregory T. Linteris

Lloyd Gewuerz, Kevin McGrattan, and Glenn Forney

Fire Research Division

Building and Fire Research Laboratory

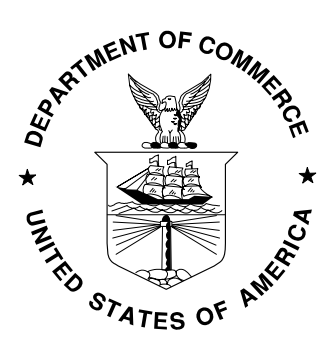

U.S. DEPARTMENT OF COMMERCE

Donald L. Evans, Secretary

TECHNOLOGY ADMINISTRATION

Phillip J. Bond, Under Secretary of Commerce for Technology NATIONAL INSTITUTE OF STANDARDS AND TECHNOLOGY

Arden L. Bement, Jr., Director 


\title{
Modeling Solid Sample Burning with FDS
}

\author{
G.T. Linteris, L. Gewuerz, K. McGrattan, and G. Forney \\ Building and Fire Research Laboratory \\ National Institute of Standards and Technology
}

October 18, 2004

\begin{abstract}
Black PMMA was burned in the cone calorimeter in two orientations (horizontal and vertical), at imposed radiant heat fluxes of $(0,5,10,25,50$, and 75$) \mathrm{kW} / \mathrm{m}^{2}$, and the visual appearance, flame size, heat release rate, and mass loss rate were recorded. Various other experimental parameters were varied. The topography of the burned samples was also recorded, and the heat flux to the sample was inferred from the variation of the mass loss over the surface of the sample. The burning was subsequently modeled using the NIST Fire Dynamics Simulator, and various experimental, numerical, and physical parameters were varied in the simulations. The results provide an indication of the ability of FDS to predict the burning of a simple solid sample, and also provide guidance concerning the importance of various experimental and numerical parameters for accurate simulation.
\end{abstract}

\section{Introduction}

The NIST Fire Dynamics Simulator (FDS) [1,2], and the companion visualization program Smokeview[3], is a widely used computational fluid dynamics package which was originally written for predicting the movement of smoke and hot gases in building fires[2]. Recently, its capabilities have been systematically extended to include fire growth and spread. Predicting these phenomena is challenging, and experimental data are required to validate the code's accuracy. Clearly, intermediate and large-scale tests are required; however they are expensive and time consuming. It is also necessary to validate the sub-grid scale models with small-scale tests. The ultimate goal of the present work is to improve the treatment of the solid phase in FDS. As a first step, small scale experiments were conducted in the NIST cone calorimeter and FDS was used to predict the burning rate. This provides some measure of FDS capacity for predicting fire growth, since an ability to predict the burning of such a simple configuration is a clear prerequisite for modeling large fires which ultimately will also involve burning on the scale of cone samples. Hence, the short term goal of this project is to assess the relative 
importance of various numerical, physical, and experimental parameters on the predicted burning of the sample. In addition to providing a validation of FDS's abilities at this scale, the tests and modeling also serve as a benchmark so that eventual changes to the treatment of the solid phase can be compared with a baseline case.

In order to avoid the complex phenomena which occur during the burning of some polymers (for example, bubbling, dripping, char formation, micro-explosions, complex time-dependent decomposition, etc.) [4], PMMA (a simple, well characterized and well behaved, non-charring, non-dripping polymer) was selected. Although it is desired to study these other parameters as well, their investigation will be conducted in future work, since their treatment is clearly beyond current modeling capabilities for burning samples.

In the experiments, the parameters varied include sample orientation (horizontal, inverted, and vertical), radiant flux ( 0 to 75$) \mathrm{kW} / \mathrm{m}^{2}$, cone presence (for the 0 flux case), and the sample edge and backing condition. In the numerical modeling, these parameters were varied, as well as those pertaining to the sample physical properties, and those relevant to the numerical solution (domain size, resolution, etc.).

\section{Experiment}

Black PMMA samples, $10 \mathrm{~cm} \times 10 \mathrm{~cm} \times 2.54 \mathrm{~cm}$, were burned in the NIST cone calorimeter (Figure 1). The samples were insulated on the back side with $6 \mathrm{~cm}$ of Kaowool ${ }^{*}$ insulation, and had $0.77 \mathrm{~mm}$ thick cardboard around the perimeter. The heat release rate of the burning sample as a function of time was determined with oxygen consumption calorimetry (assuming a heat release of 13,125 $\mathrm{kJ} / \mathrm{kg}-\mathrm{O}_{2}$ ); the visual flame size and mass loss rate were also recorded. The cone apparatus was modified from its normal operating configuration so that the surface of the cone heater closest to the sample was maintained at $2.54 \mathrm{~cm}$ from the burning PMMA sample (i.e., the cone was translated as the sample surface regressed). During the tests it was observed that the sample surface regression rate was non-uniform over the sample,

\footnotetext{
* Certain commercial equipment, instruments, or materials are identified in this paper to adequately specify the procedure. Such identification does not imply recommendation or endorsement by NIST, nor does it imply that the materials or equipment are necessarily the best available for the intended use.
} 


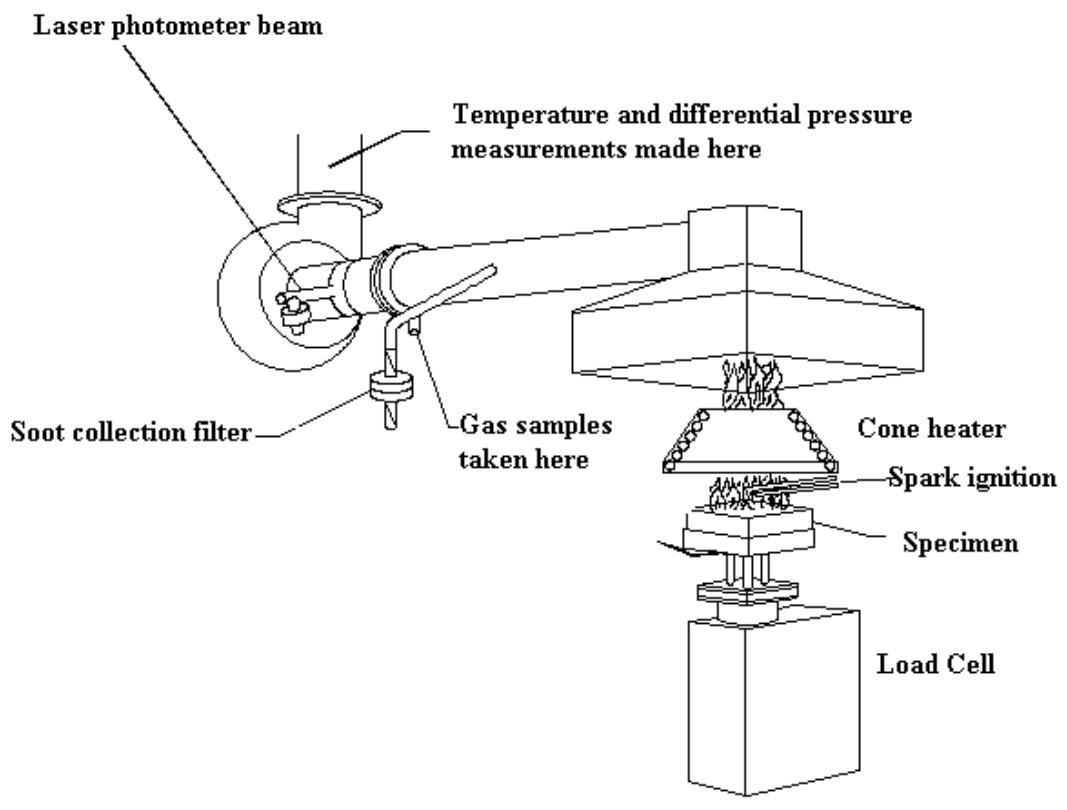

Figure 1 - NIST cone calorimeter [5].

and hence the sample final height as a function of position over the sample surface could be used to provide the varying heat flux (or regression rate) for comparison with the numerical calculations. To measure the surface height as a function of position on the sample, a custom-built system was used. Stepper motors positioned the sample under a contact-switch surface probe, which determined the local sample height. Repeating the process on a 20 x 20 grid allowed characterization of the burned sample topography.

\section{Numerical Calculations}

The burning of the cone samples was predicted with FDS version 4. The low-Mach number formulation of the Navier-Stokes equations is solved to predict the gas movement. For PMMA combustion, the MMA monomer $\left(\mathrm{C}_{5} \mathrm{H}_{8} \mathrm{O}_{2}\right)$ is assumed to be liberated from the sample surface when the surface reaches the ignition temperature. The rate of mass loss is determined from an energy balance at the surface, with all net incident energy being used to decompose and vaporize the PMMA (accounted for with a "heat of vaporization"). The code predicts the flame location based on a mixture fraction formulation, in which the fuel and oxygen consumption, as well as the heat release, occur in the grid cells for which the fuel and oxygen are present in stoichiometric proportions. Complete combustion at the flame sheet is assumed via the reaction:

$$
\mathrm{C}_{5} \mathrm{H}_{8} \mathrm{O}_{2}+6 \mathrm{O}_{2}=>5 \mathrm{CO}_{2}+4 \mathrm{H}_{2} \mathrm{O} \text {, }
$$

(although slight modifications to the stoichiometric coefficients are made to account for empirically determined yields of soot and CO). Radiation heat transfer from hot surfaces (i.e., the cone and the hot surface of the PMMA) is calculated assuming unity emissivity; 
for the gases, gray body radiation is calculated (with a prescribed soot volume fraction and otherwise transparent gases).

In order to make the run times reasonable, the code was run primarily in the 2-D mode (planar for the vertical and inverted cases, and axisymmetric for the horizontal case). Calculations were performed for samples in the horizontal, inverted, and vertical

orientation. Some 3-D calculations were also run for comparison, and to obtain the surface regression rate variation over the surface of the sample.

The experimental configuration for the horizontal and vertical cases was that of the NIST cone calorimeter as illustrated in Figure 2 and Figure 3. For the inverted case, data were taken from Olson et al. [6], and the configuration is illustrated in Figure 4. For samples with an imposed flux, the cone was located $2.54 \mathrm{~cm}$ from the top of the PMMA surface; for those with no imposed flux, the cone was typically not present in the calculation domain. All boundaries of the calculation domain (except the sample) were open (ambient pressure), except for the inverted cone case, for which there was an imposed flow up through the middle of the cone calorimeter.

\section{Experimental Results}

The data available from the experiments were flame visual images, the gas-phase heat release rate, and the sample mass loss rate, all as a function of time. In addition, the sample final mass and the topography of the burned samples were recorded. Images of the flames from burning PMMA in the horizontal configuration are shown in Figure 5 for imposed heat fluxes from the cone of: $(0,5,10,25$, and 75$) \mathrm{kW} / \mathrm{m}^{2}$. The thick black horizontal stripe across the flame image (for all except the 0 flux case) is the cone heater, which occludes the flame. The corresponding images (at $0,5,10,25$, and 75 ) $\mathrm{kW} / \mathrm{m}^{2}$ for the vertical configuration are shown in Figure 6. In these images, the cone heater is just to the left of the flame (note that unfortunately, the camera view was different for the images in Figure 6, so some flame images are clipped). The heat release rate as a function of time for the burning horizontal samples is shown in Figure 7. As the figure shows, higher imposed heat fluxes lead to higher heat release rates and shorter ignition times; once ignited, the heat release increases rapidly; and the vertical and horizontal cases yield very similar heat release rates. The data also show that minor changes to the sample configuration can significantly influence the heat release rate. For example, for the 0 flux, horizontal case (labeled $\mathrm{OH}$ ), scraping the carbon left from the burned cardboard edge at the sample perimeter, or flipping the cold cone up or down, can each have about a $20 \%$ effect on the burning rate. These effects are discussed below. 


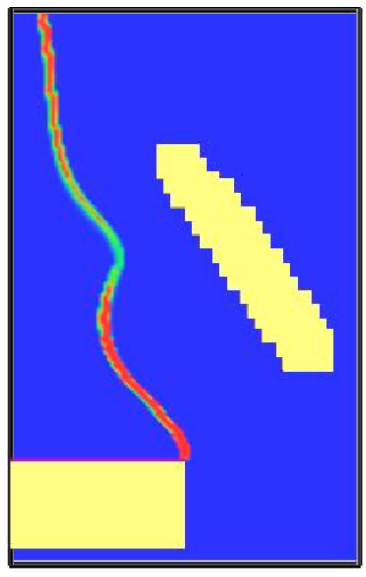

Figure 2 - Calculation domain for PMMA burning in the horizontal orientation. The calculation is 2-D axisymmetric, and the axis of symmetry is on the left side of this figure.

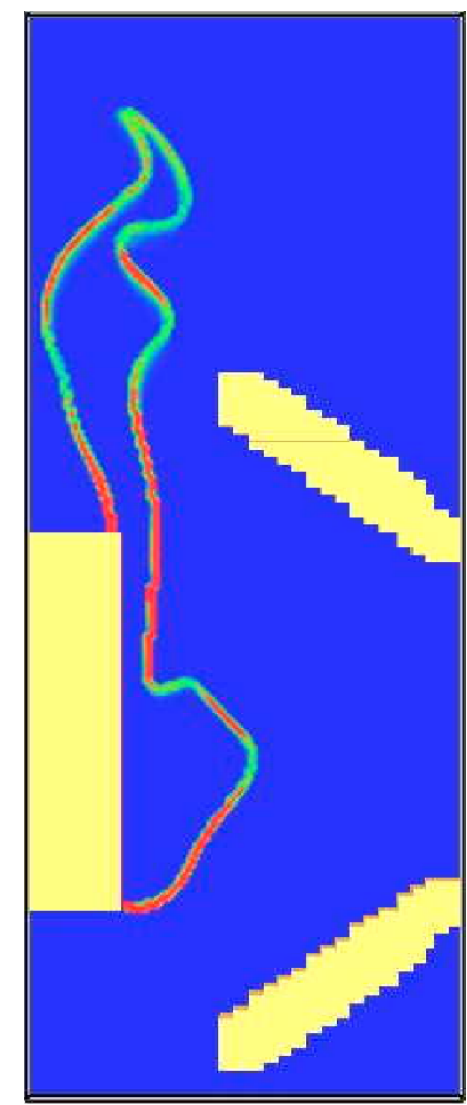

Figure 3 - Calculation domain for PMMA burning in the vertical orientation. The calculation is 2-D planar (hence the cone is also 2-D planer instead of axisymmetric).

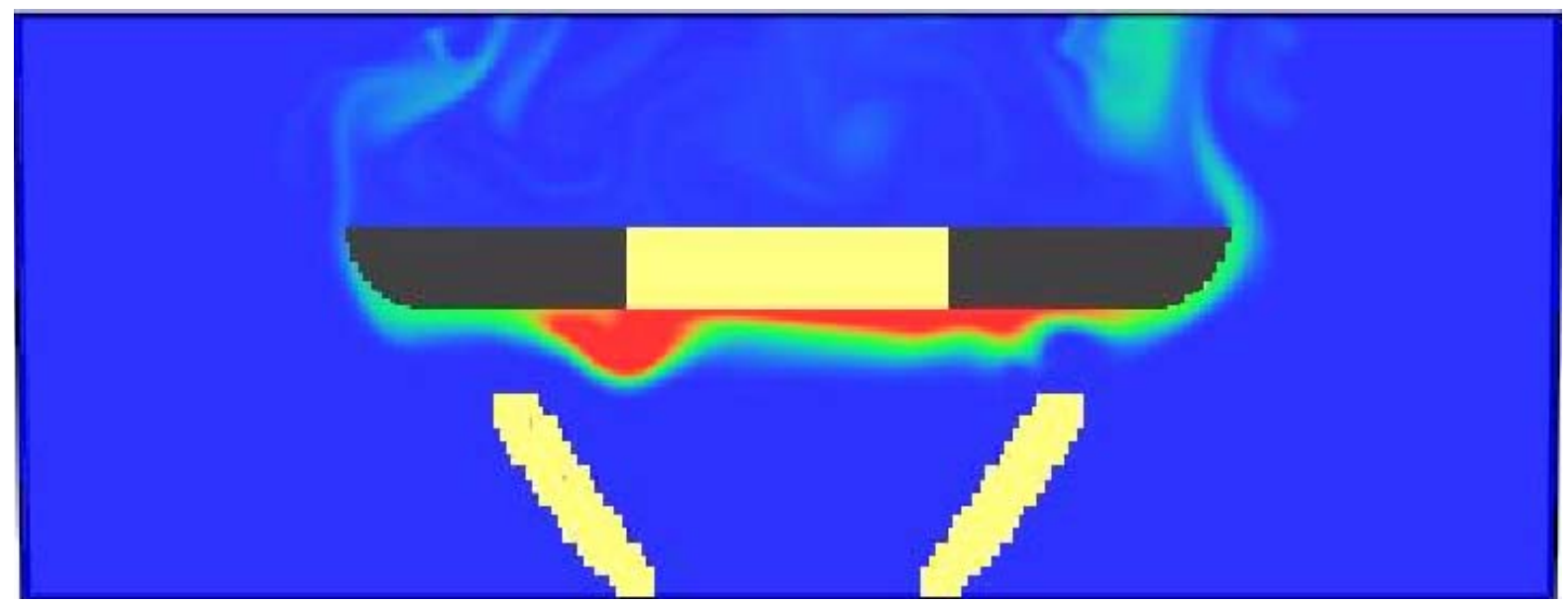

Figure 4 - Calculation domain for PMMA burning in the inverted orientation (calculation is 2-D planar). 


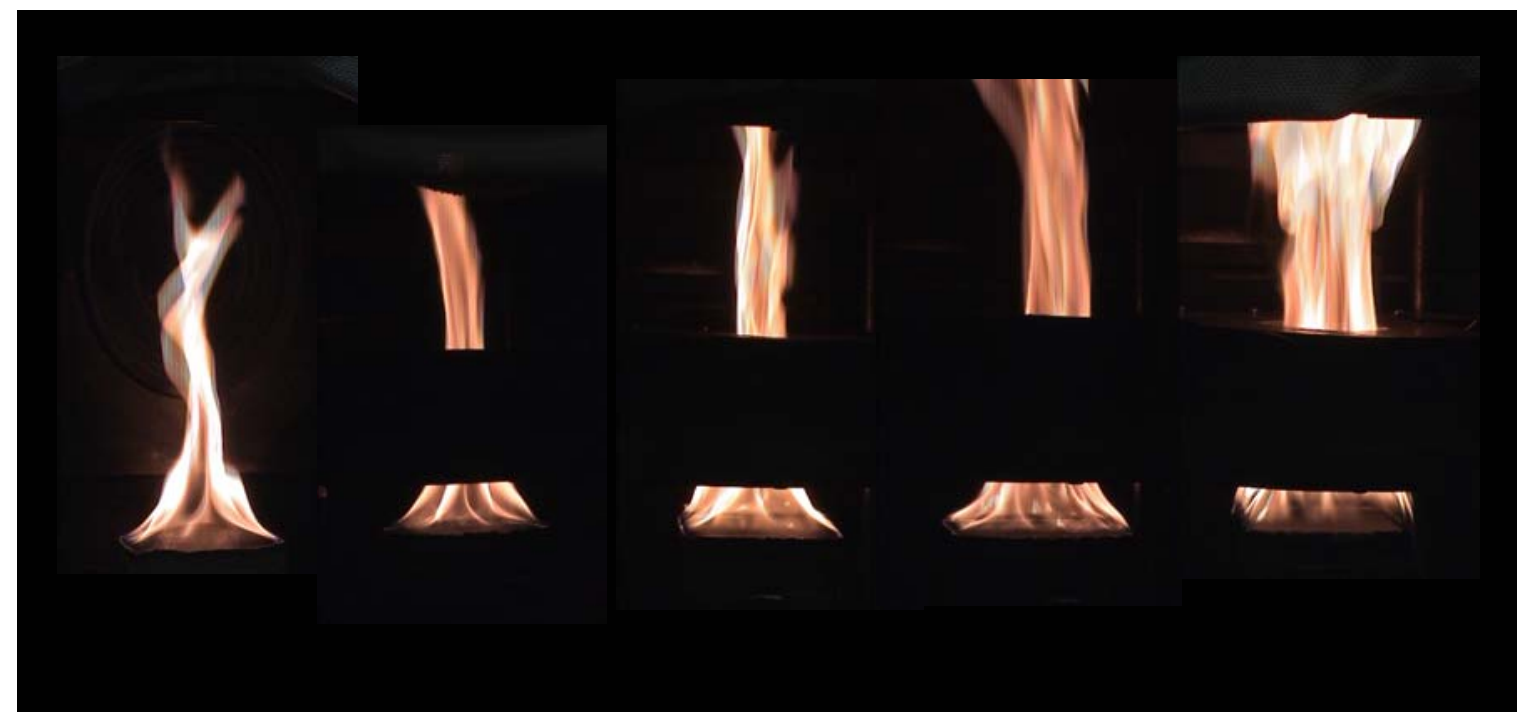

Figure 5 - Experimental flame images of PMMA samples burning in the horizontal configuration for (0, 5, 10, 25, and 75) $\mathrm{kW} / \mathrm{m}^{2}$.

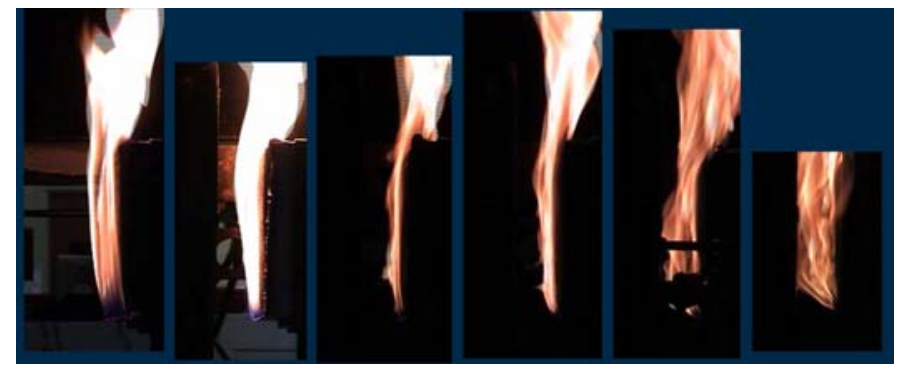

Figure 6 - Experimental flame images of PMMA samples burning in the vertical configuration for (0, 5, 10, $25,50$, and 75$) \mathrm{kW} / \mathrm{m}^{2}$. 


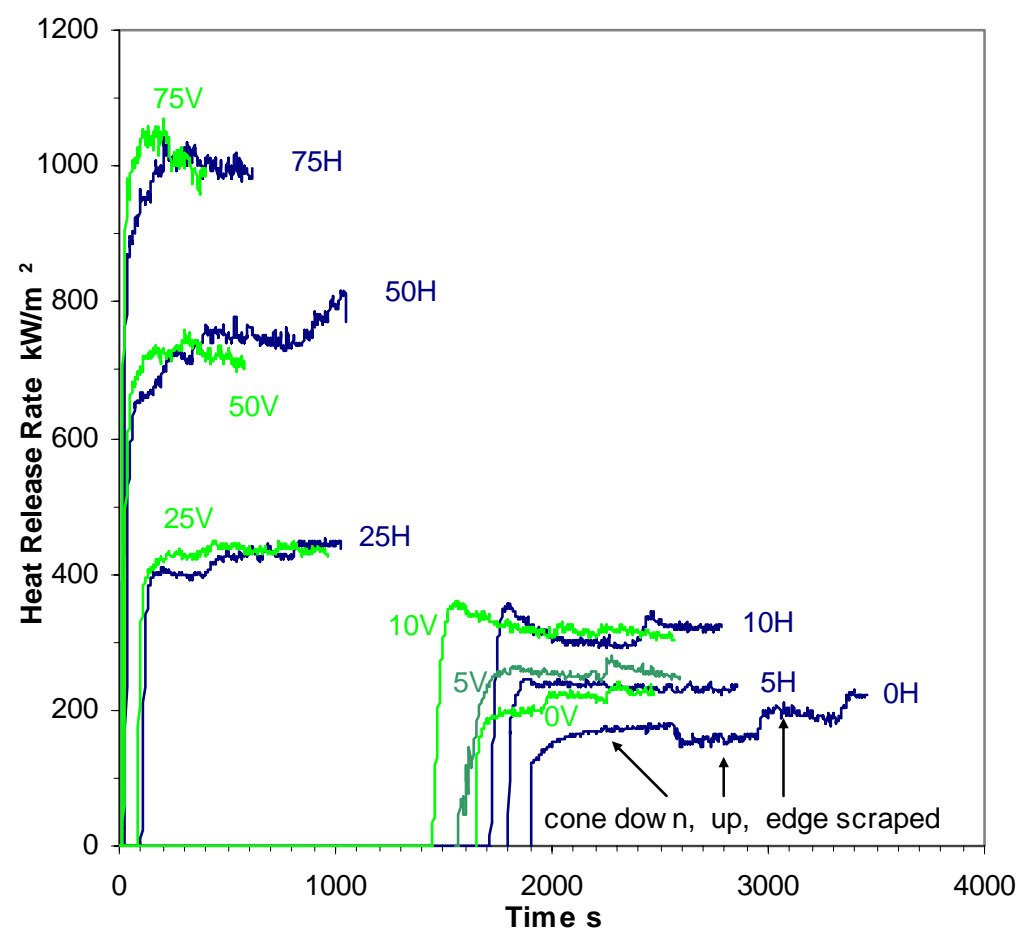

Figure 7 - Experimental heat release rate of horizontal $\mathrm{H}$ and vertical $\mathrm{V}$ samples of PMMA in the cone calorimeter for imposed heat fluxes of $(0$ to 75$) \mathrm{kW} / \mathrm{m}^{2}$. (Note: the time to the start of the heat release represents the ignition time at that heat flux; however, for $(0$ and 5$) \mathrm{kW} / \mathrm{m}^{2}$, ignition would not occur, so the curves are shown on the plot transposed $200 \mathrm{~s}$ and $100 \mathrm{~s}$, respectively, from the ignition time for the $10 \mathrm{~kW} / \mathrm{m}^{2}$ case, respectively.

The samples did not burn uniformly over their exposed surface, and the effect was more pronounced at the lower flux levels. For example, the final condition of the horizontal sample at $0 \mathrm{~kW} / \mathrm{m}^{2}$ is shown in Figure 8 . From such samples, the burning rate variation over the surface of the sample can be determined.

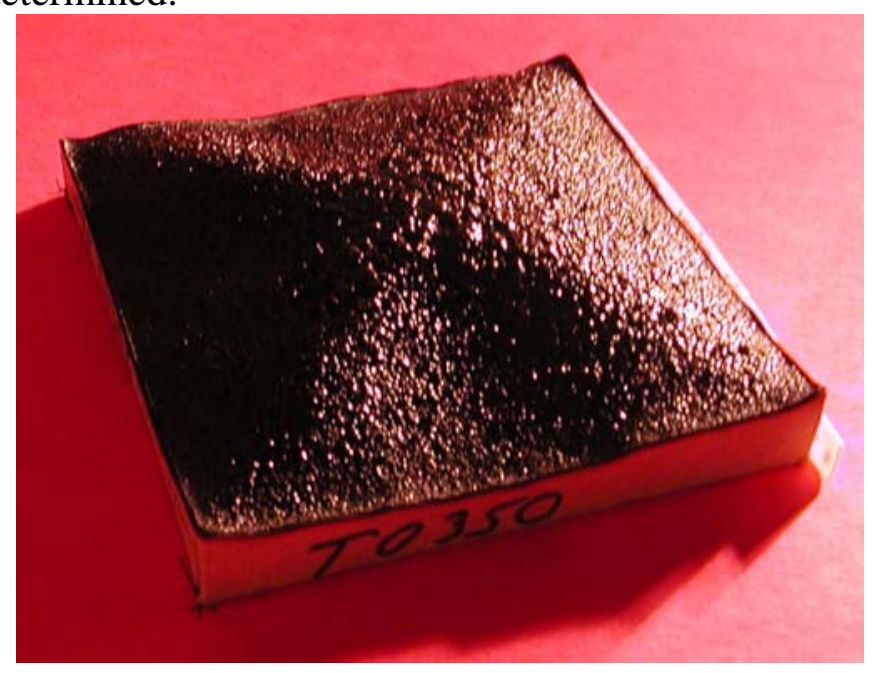

Figure 8 - Black PMMA sample, horizontally exposed to $0 \mathrm{~kW} / \mathrm{m}^{2}$ in the cone, after burning for 26 min. 


\section{Numerical Results}

The calculations were performed at the Linux cluster at BFRL of NIST, on $1.7 \mathrm{GHz}$ to $3.2 \mathrm{GHz}$. Pentium 4 machines. The default domains used were $16 \mathrm{~cm} \mathrm{x} 16 \mathrm{~cm}$ for horizontal and $27 \mathrm{~cm} \mathrm{x}$ $6 \mathrm{~cm}$ for vertical orientations. The Smokeview visualization program allows seamless investigation of the problem set up, the calculation progress, and the thermal and fluid dynamic results of the simulation, facilitating comparisons with experiments. Two-dimensional calculations in the horizontal or vertical orientation typically took $0.5 \mathrm{~h}$ or $1 \mathrm{~h}$ for $1 \mathrm{~s}$ of simulation, and 3-D calculations took $72 \mathrm{~h}$ per $1 \mathrm{~s}$ of simulation.

The input parameters for the reaction and surface properties of PMMA are listed in Table 1; these conditions represent the baseline case. The physical properties of the PMMA sample were taken from the literature [7]. In Table 1, RADIATIVE_FRACTION is set to zero so that radiation from the flame gases is calculated by FDS (the alternative is to set some fraction of the flame heat release, say $30 \%$, to be lost by radiation, rather than to solve the radiative transport equations directly). Since the computation grid is relatively fine for this calculation, the radiative transport equation should give good results and the empirically based value is not necessary.

Table 1 - FDS input file reactant and surface parameters for PMMA.

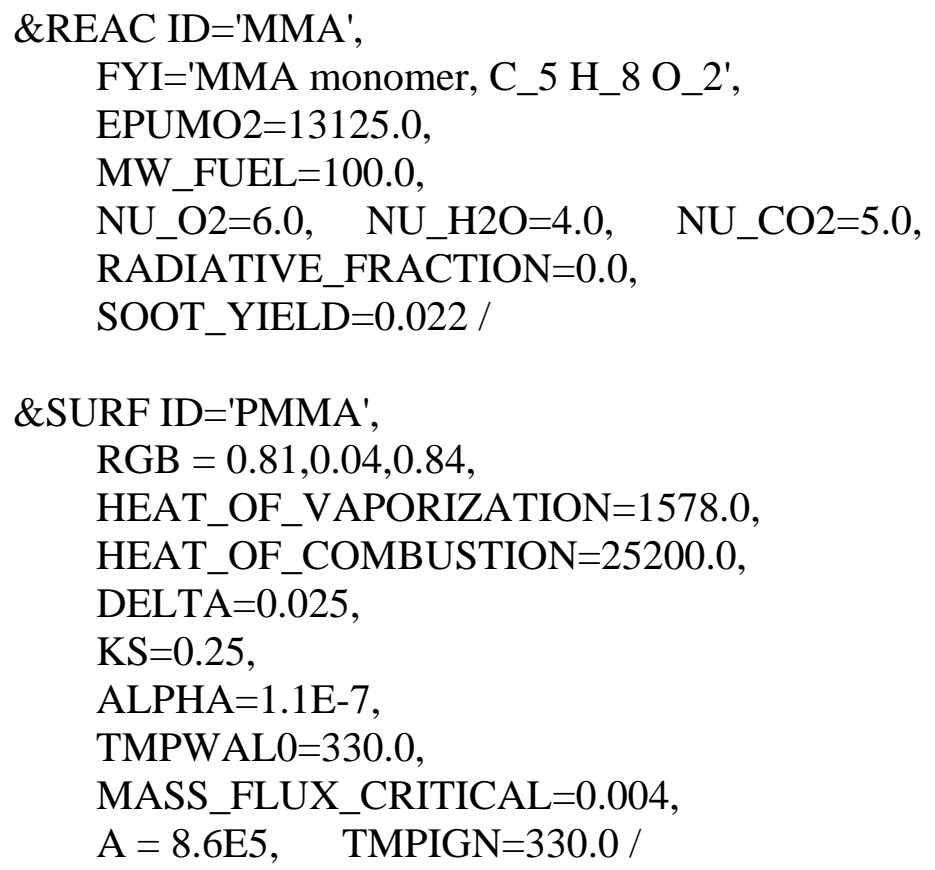

The pyrolysis behavior of the material is approximated via the last three parameters in the table. The mass loss rate of the PMMA is given by an Arrhenius rate expression, $\dot{m}^{\prime \prime}=A \rho e^{-E_{A} / R T}$, in which $\mathrm{A}$ and $\mathrm{E}_{\mathrm{A}}$ are the pre-exponential and activation energy for the overall pyrolysis reaction, $\mathrm{R}$ is the universal gas constant and $\mathrm{T}$ is the surface temperature. The three parameters $\mathrm{A}$, 
TMPIGN, and MASS_FLUX_CRITICAL are only relevant with regard to this rate expression. That is, TMPIGN is the temperature $\left({ }^{\circ} \mathrm{C}\right)$ at which the mass loss (i.e., burning) occurs. In the default condition, $A$ is prescribed $(A=8.6 E 5)$, and the code then selects $E_{A}$ such that the specified MASS_FLUX_CRITICAL is achieved at TMPIGN. Usually, a burning temperature for a material is known, but the actual Arrhenius rate parameters are not. Hence, the goal in the code is to have each material burn at the correct temperature. The Arrhenius expression is used primarily to accomplish that, while providing a smooth function that is better numerically than a step function. Of course, if the actual global Arrhenius parameters are available, they can be used directly.

The parameters varied in the calculations include those having to do with the numerical solution, the physical properties of the sample, and the experimental configuration which is modeled. The numerical parameters varied include the domain size, grid spacing, DNS or LES calculation mode, and 2-D or 3-D calculation. The physical parameters varied were the heat of vaporization, the activation energy of the thermal decomposition step, and the ignition temperature. The fidelity of the experimental description in the calculation was varied by including or excluding such effects as the presence of the exhaust flow, the lip on the sample edge, presence of the cone above the sample (in the no-flux case), and the sample backing insulation. Finally, the major experimental parameters were varied by changing the cone temperature (i.e., the imposed heat flux), and the sample orientation (horizontal, vertical, or inverted). The effects of each of these parameters on the predicted heat release rate are described below.

\section{Numerical Parameter Variation}

\section{Domain Size}

The size of the physical domain for the horizontal case was $16 \mathrm{~cm} \times 16 \mathrm{~cm}$. A plot of the calculated heat release rate (HRR) in the system as a function of time is shown in Figure 9a as the small red open symbols. (Since the heat is released in the gas phase, this HRR will be referred to as the gas-phase HRR. Conversely, one can calculate the HRR from the solid-phase mass loss rate times the heat of combustion; this will be referred to as the solid-phase HRR. Note that in the calculations, no actual energy is released within the solid phase; this naming convention merely refers to how the HRR is estimated.) The solid-phase HRR is shown by the red dashes. There is large scatter in the gas-phase HRR, as well as significant discrepancy between the gas-phase and solid-phase results, with the solid-phase HRR showing about $40 \%$ higher HRR than the average of the gas-phase HRR. As illustrated in Figure 10a, the limited physical domain leads to loss of reactants outside the domain before they are consumed, leading to a lower HRR than indicated by the burning rate (which counts all vaporized fuel as burned). For the calculation shown by the large blue circles and blue dashes, the physical domain was increased by a factor of 4 in the direction perpendicular to the horizontal sample (i.e., up) as in Figure 10b,c. With the larger domain, there is less scatter in the gas-phase HRR, the average of the gas-phase and solid-phase HRR agree better with each other, and the solid-phase HRR is about $10 \%$ lower than that calculated for the original domain. 


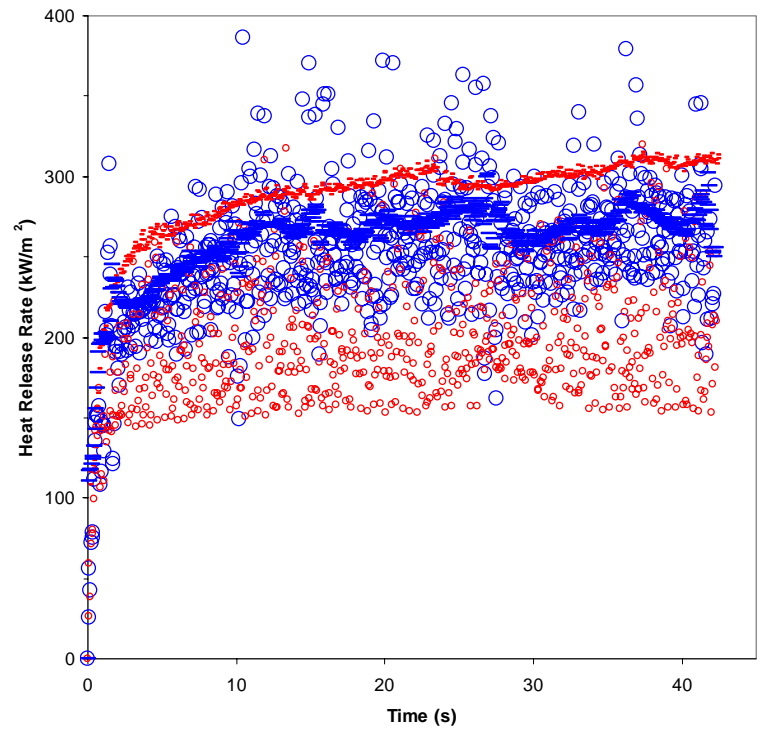

a.)

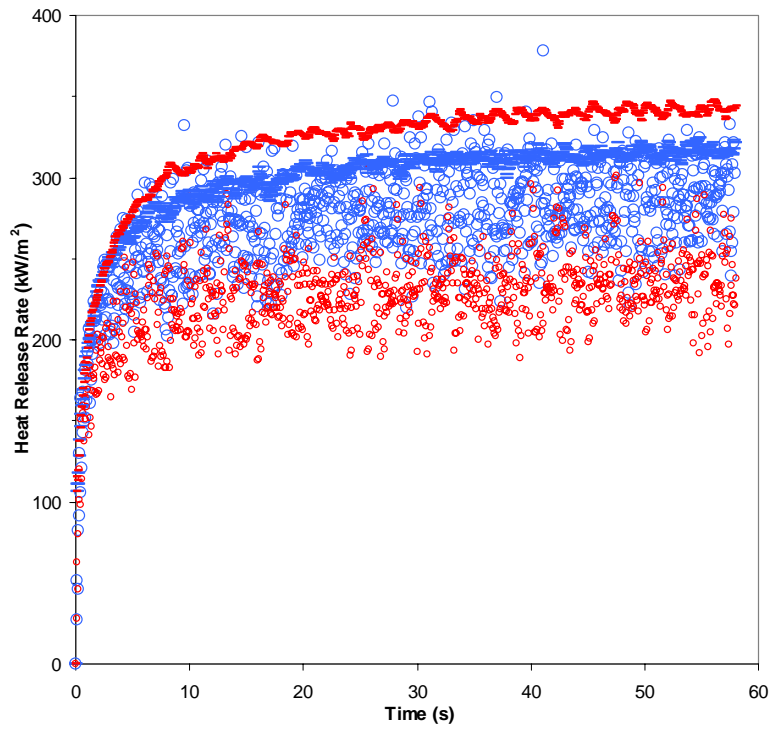

b.)

Figure 9 - Simulated heat release rate from burning PMMA a.) horizontal sample, b.) vertical sample; 2-D calculation, $1 \mathrm{~mm}$ grid spacing, $0 \mathrm{~kW} / \mathrm{m}^{2}$ imposed flux. Open symbols: calculated heat release rate from the gas phase; dashes: solid phase mass loss rate times the heat of combustion; red points are the original domain, blue points are the expanded domain: $4 \mathrm{x}$ in the $\mathrm{z}$-direction for the horizontal case, $2 \mathrm{x}$ in the $\mathrm{x}$ and $\mathrm{z}$ direction for the vertical case.

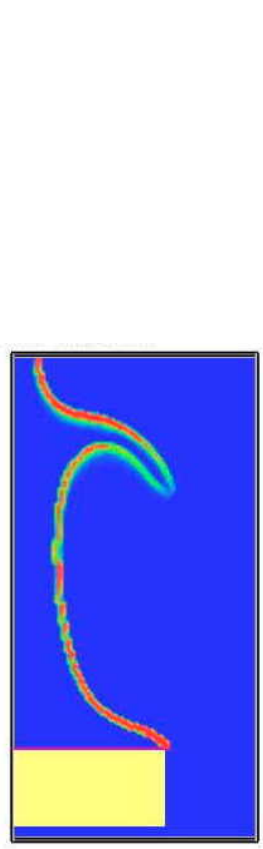

a.)
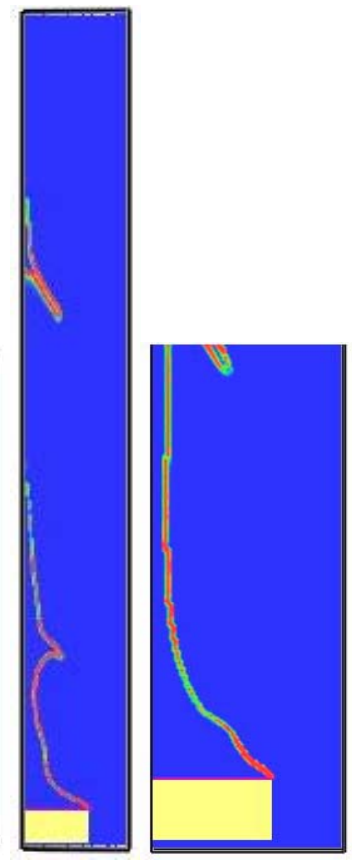

b)

c.)

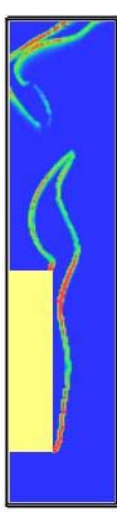

d.)

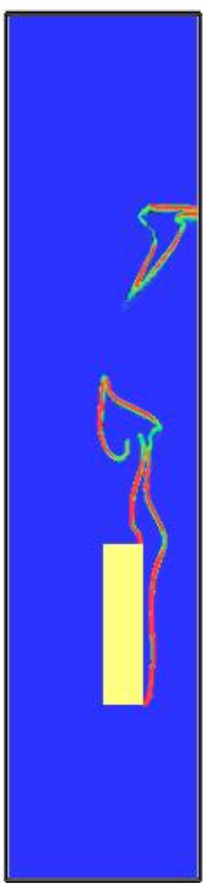

e.)

Figure 10 - Flame location from simulation; horizontal case: a.) original domain, b.) expanded by $4 x$ in the $z$, c.) magnified view of $b$.); and vertical case: $d$.) original domain, e.) expanded domain. 
For vertical samples, the results were similar (see Figure 9b): a larger domain leads to better agreement between the HRR predicted from the gas phase and the solid phase, and leads to a slightly lower heat release predicted by the solid-phase mass loss. For the vertical case, however, even with the larger domain, there is still a $10 \%$ discrepancy between the average HRR predicted from the gas phase as compared to the solid phase, indicating that a still larger domain may be necessary. The flames escaping from the original calculation domain for the vertical case are shown in Figure 10d, and case of the expanded domain in Figure 10e. Note that the some of this discrepancy between the mass loss-based HRR and that calculated to occur in the gas phase may also be numerically induced.

\section{Grid Spacing}

For the vertically-oriented PMMA sample, calculations were performed using grid spacings of either $1 \mathrm{~mm}$ or $2 \mathrm{~mm}$ (in both the $\mathrm{x}$ and $\mathrm{z}$ directions), as shown in Figure 11. The results of these calculations, as illustrated in Figure 12, show a significant drop in heat release rate (about a factor of two) for the coarser grid. Furthermore, with a lower resolution, the gas-based and solid-based HRR tend to converge and the gas-based rate shows less variation. (These effects may be numerically induced.)

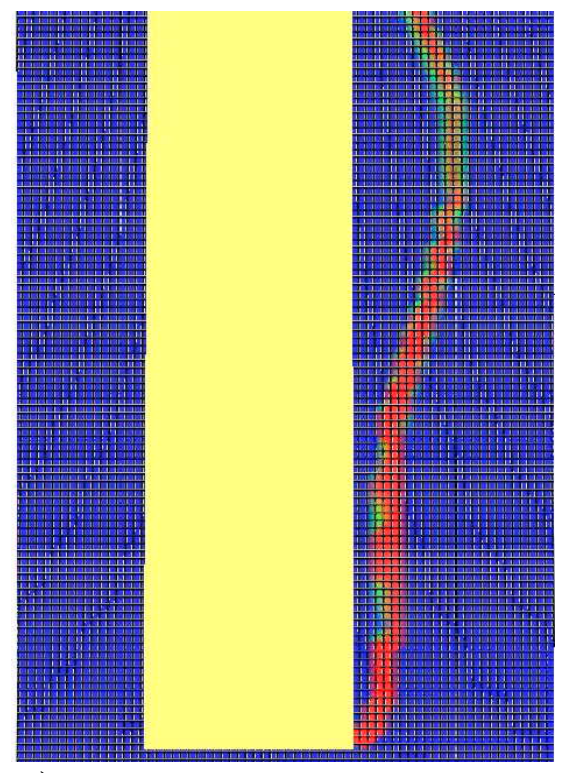

a.)

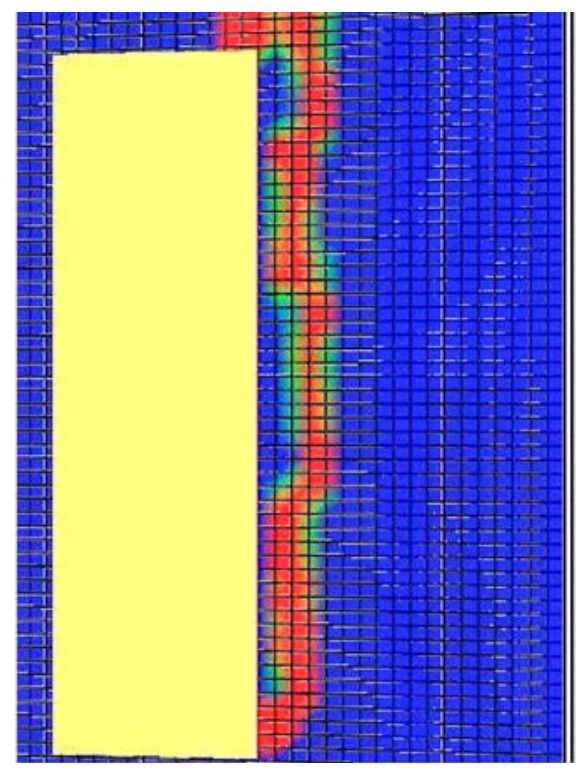

b.)

Figure 11 - Smokeview images of the simulated flame near the burning vertical PMMA surface for grid spacing of a.) $1 \mathrm{~mm}$, and b.) $2 \mathrm{~mm}$. 


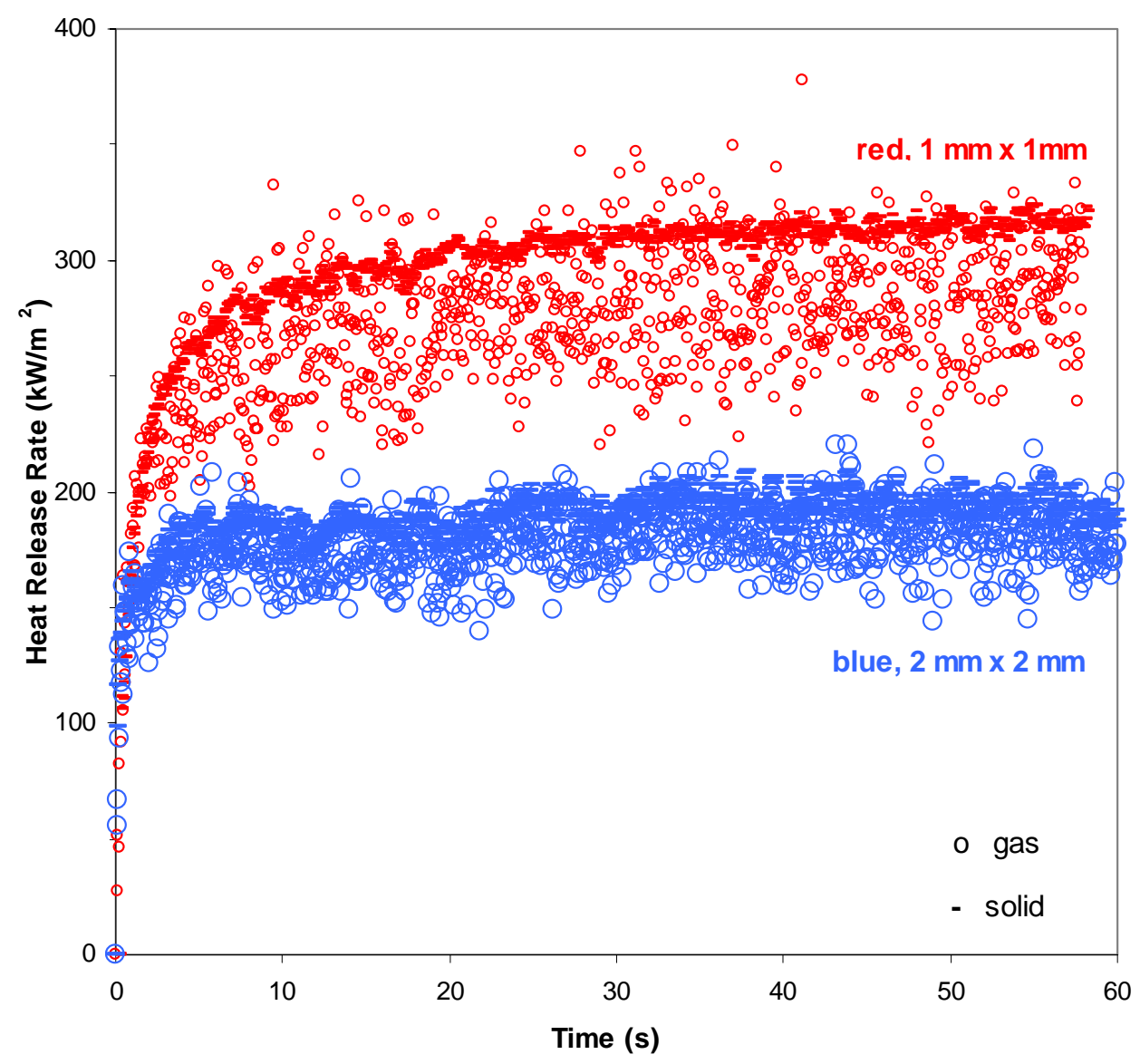

Figure 12 - Heat release rate from the gas phase (open circles) or from the solid phase (mass loss rate $x$ heat of combustion, bars) from calculations done with $1 \mathrm{~mm}$ (red) or $2 \mathrm{~mm}$ (blue) grid spacing. 


\section{Calculation Method - DNS/LES}

Two types of calculations can be performed in FDS: Large Eddy Simulation (LES) and Direct Numerical Simulation (DNS), differing in their treatment of the sub-grid-scale dynamic viscosity term of the momentum equation. Although the grid resolution is fine enough for the present calculations that there may not be much difference between the two, we ran calculations in both modes. Also, in the LES calculations, the baroclinic vorticity term in the momentum equation is typically ignored (a reasonable simplification for larger-scale calculations). For the present small-scale application, however, inclusion of baroclinic vorticity term does affect the results, and hence we performed LES calculations with and without this term. The calculated HRR (based on the mass loss rate) is shown in Figure 13 (horizontal) and Figure 14 (vertical) for calculations in DNS mode, LES mode, and LES with the baroclinic vorticity term retained. The LES case without baroclinic vorticity predicted the HRR to be a few percent higher than the DNS case, while surprisingly, the LES case with baroclinic vorticity predicted HRR $7 \%$ and $16 \%$ higher than DNS case for the horizontal and vertical orientations, respectively.

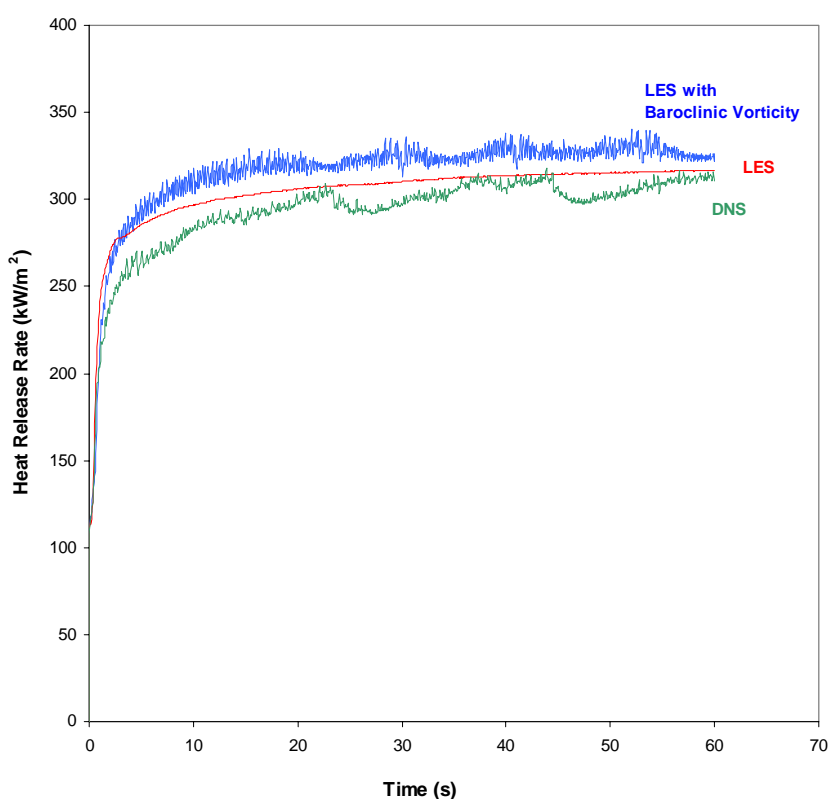

Figure 13 - Heat release rate (based on solid sample mass loss rate) for horizontal PMMA, $0 \mathrm{~kW} / \mathrm{m}^{2}$ incident flux, calculated via DNS, LES, or LES (with baroclinic vorticity).

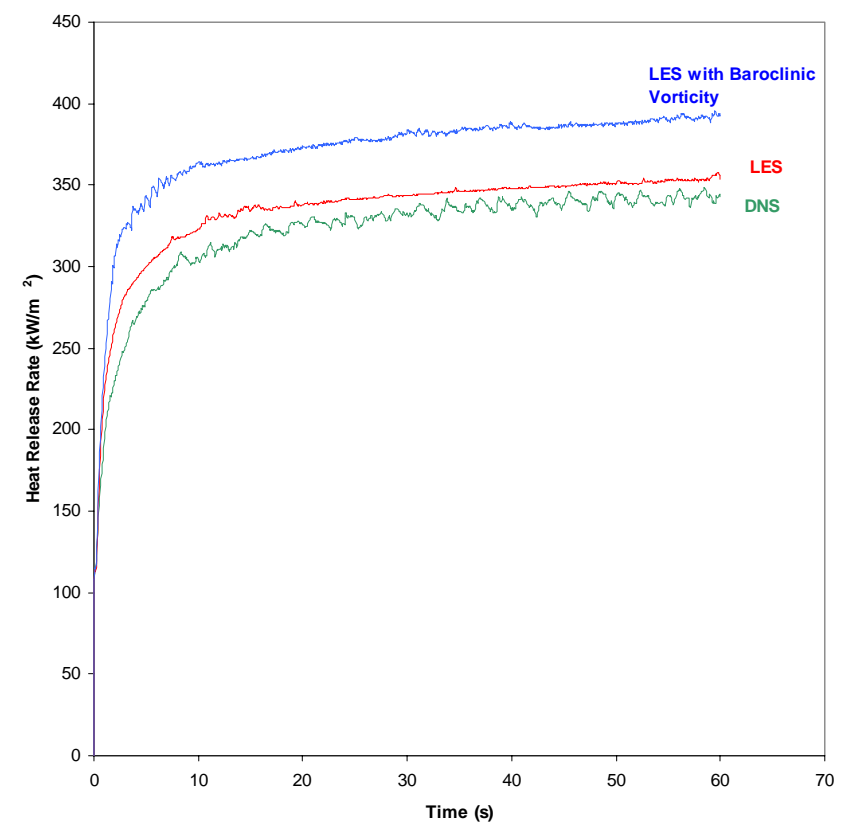

Figure 14 - Heat release rate (based on solid sample mass loss rate) for vertical PMMA, $0 \mathrm{~kW} / \mathrm{m}^{2}$ incident flux, calculated via DNS, LES, or LES (with baroclinic vorticity).

Three-dimensional Analysis

All of the previous simulations were performed using a two-dimensional analysis. FDS is also capable of performing calculations in three dimensions (with run times increased by a factor of about 100). One case for each of the horizontal and vertical sample scenarios (each 
burning with zero imposed flux from the cone) was calculated in three-dimensional mode. For the horizontal sample, there is not much variation in the heat release rate as the simulation mode is changed. Therefore, the faster, two-dimensional mode appears to be sufficiently accurate. More of a difference is evident for the vertical orientation, with the two-dimensional mode predicting a $7 \%$ lower heat release rate. This lower HRR in the 2-D mode for the vertical samples may be due to edge effects: the actual samples (as well as the 3-D calculation) show significant burning at the lateral edges of the samples which is not captured in the 2-D planar (i.e., infinite length, no edges) calculation. Since the horizontal 2-D calculation is done in the axisymmetric mode, it has a complete edge and would not experience this inaccuracy.
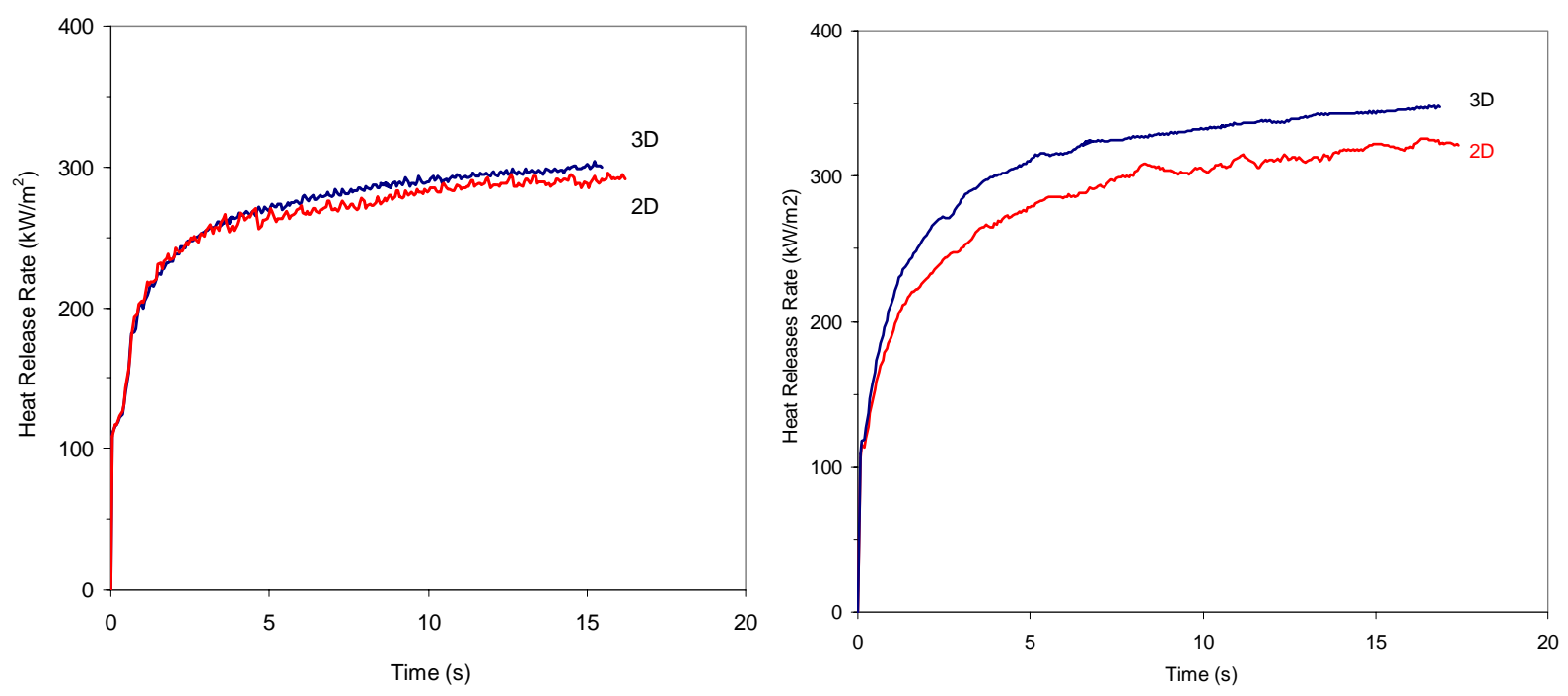

Figure 15 - Heat release rate (solid-based) from 2-D and 3-D FDS calculations, 1 mm grid spacing, original domain, horizontal (left) and vertical (right) PMMA samples, $0 \mathrm{~kW} / \mathrm{m}^{2}$ flux.

\section{Physical Parameter Variation}

The physical parameters necessary for predicting the burning rate are the specific heat, thermal conductivity, density, heat of combustion, heat of vaporization (i.e., decomposition), and kinetic parameters describing the mass loss rate as a function of temperature. In the numerical tests, we varied the heat of vaporization, the overall activation energy of the decomposition process, and the ignition temperature (i.e., the characteristic temperature at which mass loss occurs).

\section{Heat of Vaporization}

To determine the effect of the heat of vaporization in the FDS input file, calculations for a horizontal sample were run using values of $1578 \mathrm{~kJ} / \mathrm{kg}$ (baseline case) and $1420 \mathrm{~kJ} / \mathrm{kg}(10 \%$ reduced) for this parameter. Both of these cases were run with an imposed heat flux of $0 \mathrm{~kW} / \mathrm{m}^{2}$ and $75 \mathrm{~kW} / \mathrm{m}^{2}$, as illustrated in Figure 16. A lower heat of vaporization produced a higher heat release rate. This is expected since the mass loss rate $\dot{m}^{\prime \prime}$ is equal to the ratio of the net heat flux 
to the heat of vaporization, $\frac{\dot{q}_{n e t}^{\prime \prime}}{L_{v}}$, and the HRR is the product of the mass loss rate and the heat of combustion of PMMA. The difference between the baseline case and the $10 \%$ lower heat of vaporization was slightly more significant in the high flux case (approximately 8\%) than in the no flux case (approximately 5\%). To first order, since all of the heat released goes into vaporizing the PMMA, a $10 \%$ decrease in $\mathrm{L}_{\mathrm{v}}$ is expected to give a $10 \%$ increase in burning rate; however, some of the heat feedback to the sample surface also goes into conductive losses and these are a larger fraction of the total heat flux to the sample for the 0 imposed flux case. This may explain the lesser effect for the no flux case.

As shown far below in Figure 28, for horizontal PMMA, decreasing the heat of vaporization improved agreement with the experiment, especially for the higher fluxes. For the vertical cases, however, lowering the heat of vaporization $10 \%$ may not improve the FDS prediction, since the calculated heat release rate is fairly close to the measured value at $75 \mathrm{~kW} / \mathrm{m}^{2}$, and lowering the heat of vaporization would increase the heat release rate at that flux.

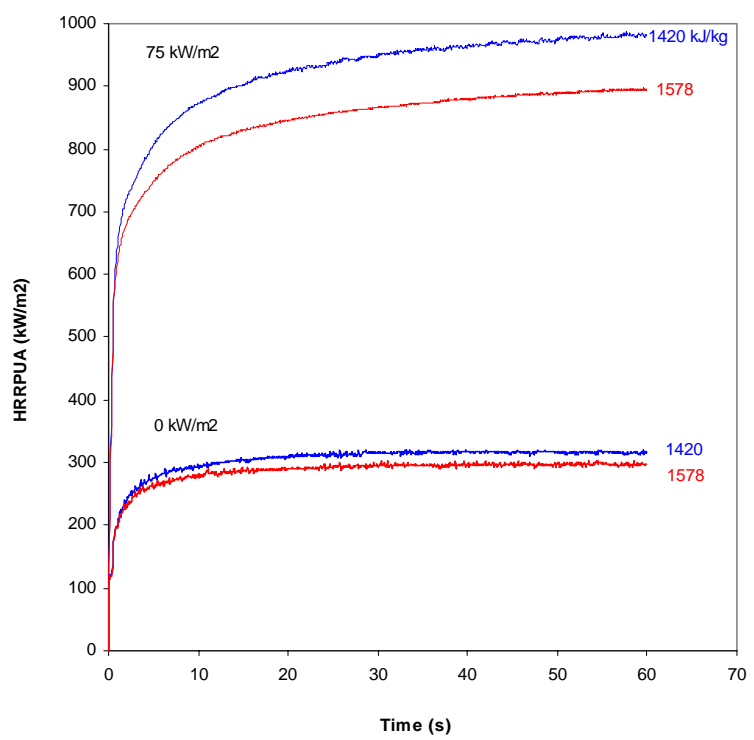

Figure 16 - Calculated heat release rate as a function of time for horizontal PMMA with imposed heat fluxes of $0 \mathrm{~kW} / \mathrm{m}^{2}$ and $75 \mathrm{~kW} / \mathrm{m}^{2}$, using the base value of the heat of vaporization $(1578 \mathrm{~kJ} / \mathrm{kg})$, and a value $10 \%$ lower $(1420 \mathrm{~kJ} / \mathrm{kg})$.

\section{Ignition Temperature}

In the FDS user's manual syntax, the "ignition temperature" basically specifies the temperature at which the sample vaporizes (like a boiling point for a liquid fuel). A higher ignition temperature decreases the heat transfer rate to the sample by convection, and increases the heat loss rate by radiation. We varied the ignition temperature of PMMA by $\pm 50{ }^{\circ} \mathrm{C}$ around the literature value of $330{ }^{\circ} \mathrm{C}$, for horizontal PMMA burning with an imposed flux of (0 and $75) \mathrm{kW} / \mathrm{m}^{2}$. For these calculations, the pre-exponential factor was set to $8.65 \times 10^{5}$, at a mass flux of $0.004 \mathrm{~kg} / \mathrm{m}^{2} / \mathrm{s}$, and the code determined the necessary activation energy to match that 
mass flux at that ignition temperature. As shown in Figure 17, a $100{ }^{\circ} \mathrm{C}$ increase in the ignition temperature gives a $10 \%$ drop in the mass loss rate for the high-flux case, and a $15 \%$ drop for the low flux case. The heat loss by radiation $\dot{q}_{r, \text { loss }}^{\prime \prime}$ can be estimated from the radiation heat transfer equation

$$
q_{r, \text { loss }}^{\prime \prime}=\varepsilon \sigma\left(T_{s}^{4}-T_{a m b}^{4}\right)
$$

which can then be compared with the net heat flux into the sample $\dot{q}_{n e t}^{\prime \prime}$. The net heat flux $\dot{q}_{n e t}^{\prime \prime}$ can be estimated from the heat release rate $\dot{q}_{\text {rel }}^{\prime \prime}$ since

$$
\dot{q}_{r e l}^{\prime \prime}=\dot{m}^{\prime \prime} \Delta H_{C} \quad \text { and } \quad \dot{q}_{n e t}^{\prime \prime}=\dot{m}^{\prime \prime} \cdot L_{v}
$$

in which $\Delta H_{C}$ is the heat of combustion and $\mathrm{L}_{\mathrm{v}}$ is the heat of vaporization. From Figure 16, the FDS-predicted heat release rate for incident radiant fluxes of $0 \mathrm{~kW} / \mathrm{m}^{2}$ and $75 \mathrm{~kW} / \mathrm{m}^{2}$ is about $310 \mathrm{~kW} / \mathrm{m}^{2}$ and $890 \mathrm{~kW} / \mathrm{m}^{2}$, respectively, which implies a net heat input going to pyrolysis of 19 $\mathrm{kW} / \mathrm{m}^{2}$ and $56 \mathrm{~kW} / \mathrm{m}^{2}$. For surface temperatures of $280^{\circ} \mathrm{C}$ and $380^{\circ} \mathrm{C}$, the predicted radiant heat loss is $5.3 \mathrm{~kW} / \mathrm{m}^{2}$ and $10.3 \mathrm{~kW} / \mathrm{m}^{2}$, or a difference of about $5 \mathrm{~kW} / \mathrm{m}^{2}$ between $280{ }^{\circ} \mathrm{C}$ and $380{ }^{\circ} \mathrm{C}$. Hence, the $5 \mathrm{~kW} / \mathrm{m}^{2}$ higher heat losses is about the right magnitude for the high-flux case (about $10 \%$ of the total energy going into pyrolysis), but too high (by a factor of two) for the low-flux case. That is, the lower burning rate of the low-flux case caused by a higher ignition temperature is not as low as one would expect based just on the higher radiative losses at the higher temperature. (Note that in the calculation, the outer edge of the PMMA is specified as non-burning, and is set to the same temperature as the ignition temperature, so lateral conductive losses are not the reason for the lower burning rate at the higher ignition temperature.)

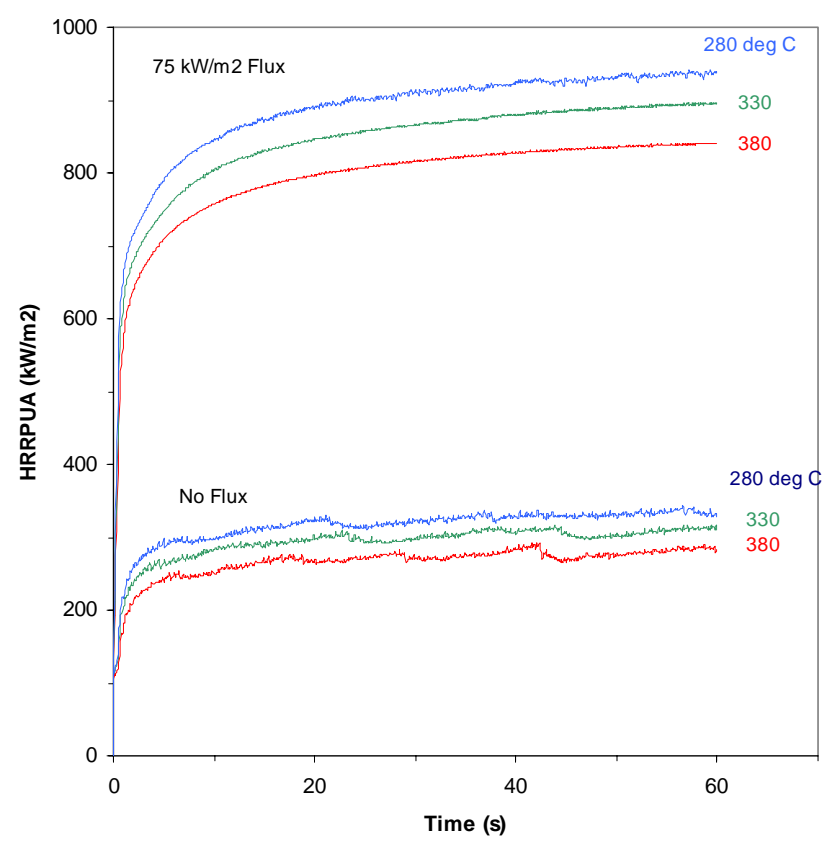

Figure 17 - Calculated variation of heat release rate with changes to the ignition temperature for horizontal PMMA at $0 \mathrm{~kW} / \mathrm{m}^{2}$ and $75 \mathrm{~kW} / \mathrm{m}^{2}$ imposed flux. 


\section{Activation Energy (E)}

In order to test the sensitivity of the burning rate to the Arrhenius parameters, we specified $\mathrm{E}_{\mathrm{A}}$ as between (20 and 50) kcal/mol, while selecting A to give the selected mass flux $\left(0.004 \mathrm{~kg} \mathrm{~m}^{-2} \mathrm{~s}^{-1}\right)$ at the experimental value of the surface temperature $\left(330^{\circ} \mathrm{C}\right)$. The results of the calculations are shown in Figure 18, in which the heat release rate as a function of time for horizontal PMMA is shown for the two values of $\mathrm{E}_{\mathrm{A}}$, for the low and high imposed flux cases. Raising the activation energy from (20 to 50) $\mathrm{kcal} / \mathrm{mol}(83 \mathrm{~kJ} / \mathrm{mol}$ to $209 \mathrm{~kJ} / \mathrm{mol}$ ) raises the heat release rate by about $11 \%$ for the low and high imposed flux cases. This is due mostly to changes in the surface temperature as the activation energy changes. As shown in Figure 19, raising $\mathrm{E}_{\mathrm{A}}$ from $83 \mathrm{~kJ} / \mathrm{mol}$ to $209 \mathrm{~kJ} / \mathrm{mol}$ lowers the surface temperature from $380{ }^{\circ} \mathrm{C}$ to $350{ }^{\circ} \mathrm{C}$. This drop in temperature lowers the radiant heat losses from the surface by about $2 \mathrm{~kW} / \mathrm{m}^{2}$, which is just about $10 \%$ of the heat going into pyrolysis for the low-flux case, in agreement with the increase in burning rate for the higher $\mathrm{E}_{\mathrm{A}}$ in this case. It should be noted, however, that this counter-intuitive behavior of the surface temperature (decreasing with increasing $E_{A}$ ) is a manifestation of the particular value used for the mass loss rate $\left(0.004 \mathrm{~kg} \mathrm{~m}^{-2} \mathrm{~s}^{-1}\right)$ at the given surface temperature $\left(330{ }^{\circ} \mathrm{C}\right)$. If the mass loss rates were matched at a higher value, the slope in Figure 19 would be positive and the change of heat release per unit area the opposite of that shown. The present exercise is still useful, however, for examining the magnitude of the sensitivity of the burning rate with respect to the activation energy.

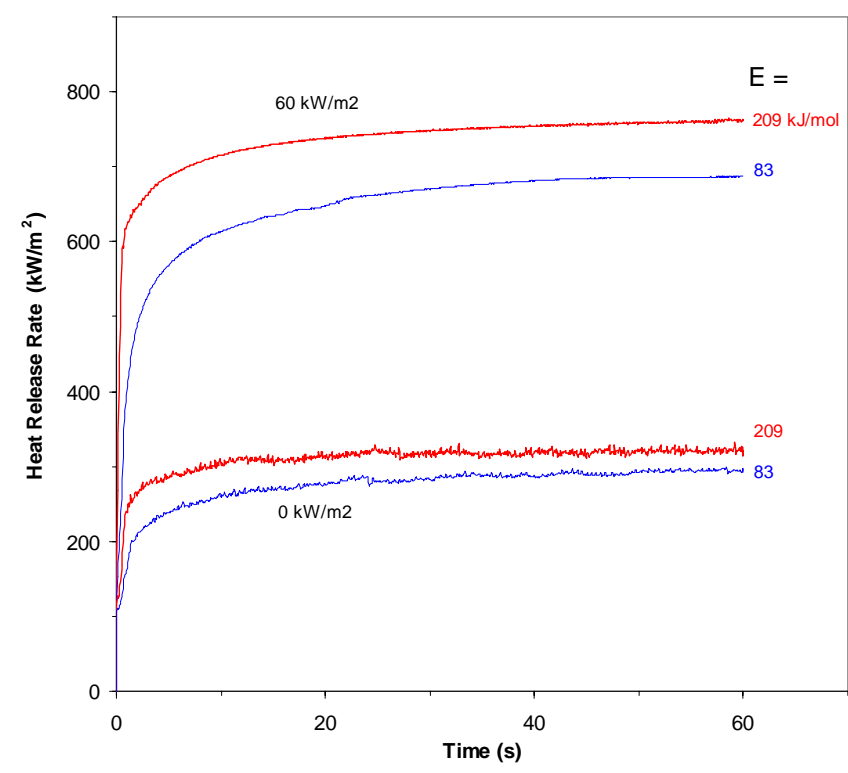

Figure 18 - Calculated heat release rate of horizontal PMMA for $0 \mathrm{~kW} / \mathrm{m}^{2}$ and $75 \mathrm{~kW} / \mathrm{m}^{2}$ imposed fluxes for values of $E_{A}$ of $20 \mathrm{kcal} / \mathrm{mol}$ and $50 \mathrm{kcal} / \mathrm{mol}$.

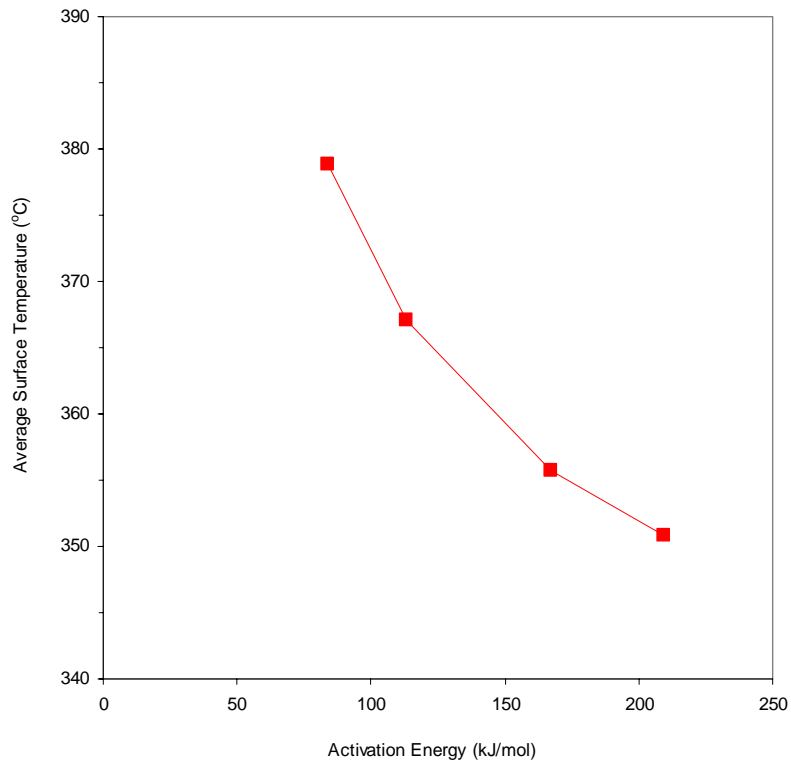

Figure 19 - Calculated variation in surface temperature resulting from different values of the activation energy. 


\section{Experimental Parameter Variation}

\section{Cone Heater Geometric Effects}

FDS calculations were performed with and without the presence of a cone heater. For these calculations, the cone had no heat capacity, so the effects are only due to changes to the flowfield, and to the radiant heat feedback from the unpowered cone (as compared to radiation from the ambient). In the experiment, when the cone was positioned above the burning horizontal sample, the flame gases heated it to about $102{ }^{\circ} \mathrm{C}$. In the simulation, its temperature was set to either $20{ }^{\circ} \mathrm{C}$ for checking the effect on the flow-field, or to $110{ }^{\circ} \mathrm{C}$ to assess changes to the radiant feedback. Figure 20 shows the heat release rate with and without a cold $\left(20^{\circ} \mathrm{C}\right)$ and warm $\left(110^{\circ} \mathrm{C}\right)$ cone present in the calculation domain. There is very little difference between the warm and cold cone, and only a $3 \%$ difference between them and the case with the cone absent. The lack of effect of the warm vs. cold cone is consistent with the small magnitude of the radiation from the cone at these temperatures (the cone flux at $110^{\circ} \mathrm{C}$ is about $5 \%$ of the heat flux from the flame to the PMMA surface). The results for cone vs. no cone are in contrast to the experiment, for which removing the cone decreased the HRR $18 \%$ rather then the few percent increase predicted by the calculations. For the vertical case (Figure 21), the calculations predict an $8 \%$ increase in the burning rate with the cone removed.

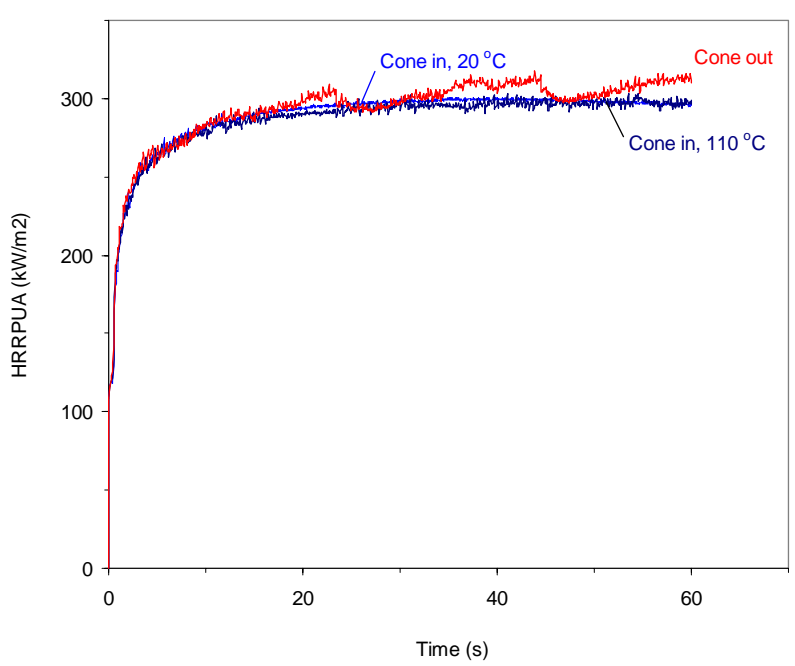

Figure 20 - Calculated heat release rate from horizontal PMMA with and without the cone heater present in the flowfield $\left(\mathrm{T}_{\text {cone }}=20^{\circ} \mathrm{C}\right.$ or $\left.110^{\circ} \mathrm{C}\right)$.

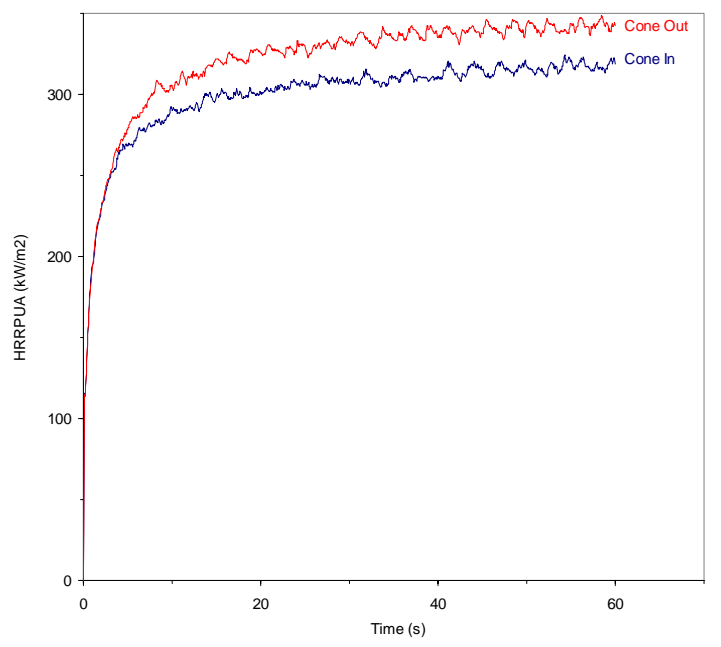

Figure 21 - Calculated heat release rate from vertical PMMA with and without the cone heater present in the flowfield $\left(\mathrm{T}_{\text {cone }}=20^{\circ} \mathrm{C}\right)$. 


\section{Sample Backing}

The code was run with and without an insulating backing on the PMMA sample. Figure 22 shows the predicted heat release of horizontal PMMA, $0 \mathrm{~kW} / \mathrm{m}^{2}$ imposed flux, with and without insulation. There is little difference in the calculated results (although the case with the insulation is somewhat smoother). Experiments were run for a vertical sample at $10 \mathrm{~kW} / \mathrm{m}^{2}$ imposed flux, with and without the insulating backing, and no measurable difference was found. The reason for the small difference between the two cases (in both the experiments and calculations) is that, due to run-time limitations, the calculation was only run for $60 \mathrm{~s}$ and not much of the heat would have penetrated to the backside in this time (the thermal time constant for heat conduction through the sample is between $1 \mathrm{~h}$ and $2 \mathrm{~h}$ ).

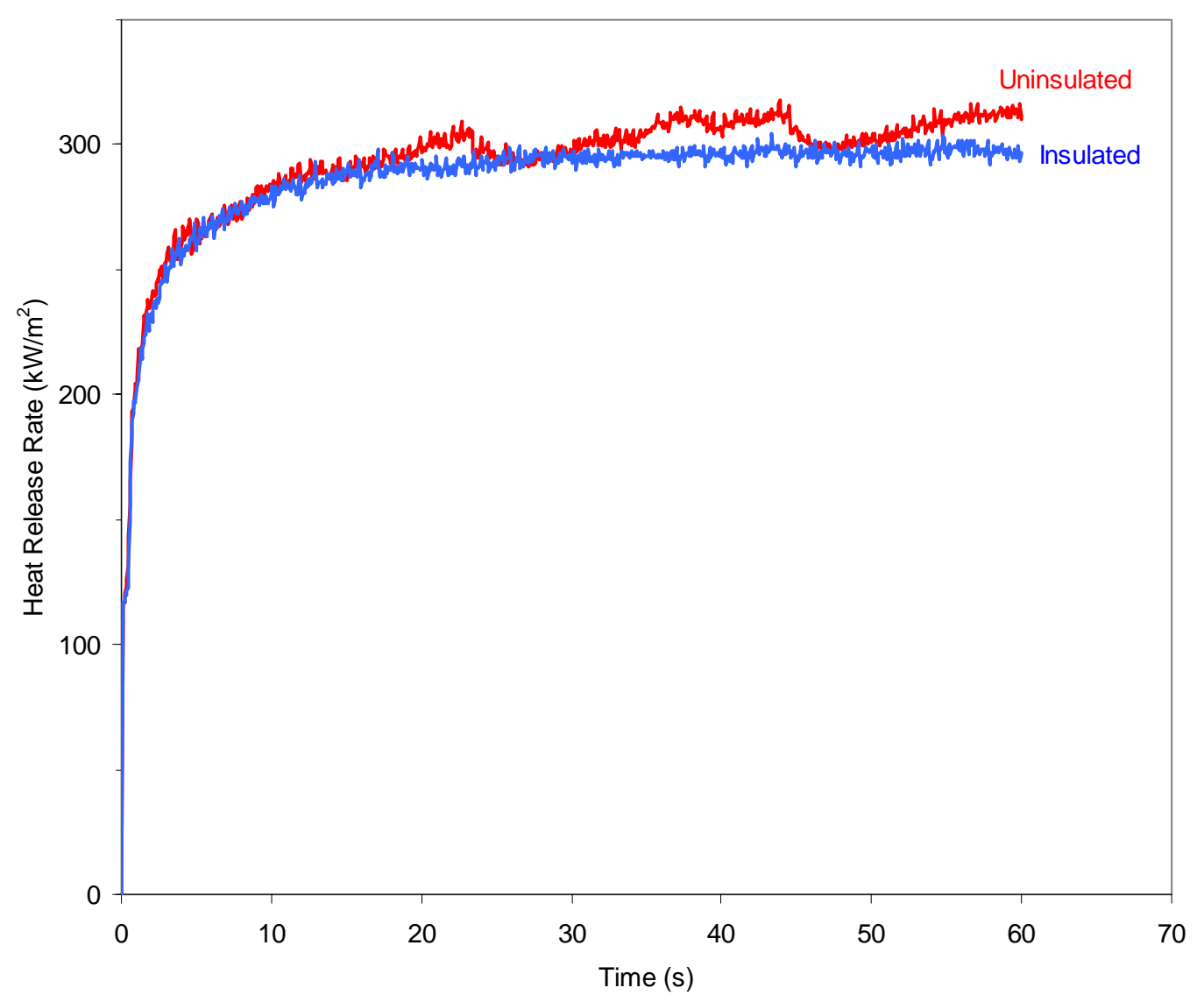

Figure 22 - Calculated heat release rate of horizontal PMMA, $0 \mathrm{~kW} / \mathrm{m}^{2}$ imposed flux, with and without an insulating backing on the cone sample. 


\section{Sample Edge Conditions}

Edge effects in the cone sample are known to affect the burning rate [8]. In the actual cone calorimeter experiments, the PMMA sample is surrounded by a cardboard strip. As the sample burns, a "lip" of char from the cardboard builds up around the edges and is either left in place or scraped away. This scraping has a significant effect on the heat release rate of the sample, as shown in Figure 7, which indicates a $20 \%$ higher burning rate when the lip is scrapped away. In FDS (2-dimensional mode), this was simulated by creating a thin inert lip at two and four millimeters above the sample surface and giving it a constant temperature equal to the ignition temperature of the PMMA $\left(330{ }^{\circ} \mathrm{C}\right.$ ). The results (Figure 23) show that $2 \mathrm{~mm}$ and $4 \mathrm{~mm}$ lips reduce the burning rate by $25 \%$ and $40 \%$. This is consistent with the size of the lip formed during the experiment, and the magnitude of the increase in burning rate after removing the lip (as shown in Figure 7).

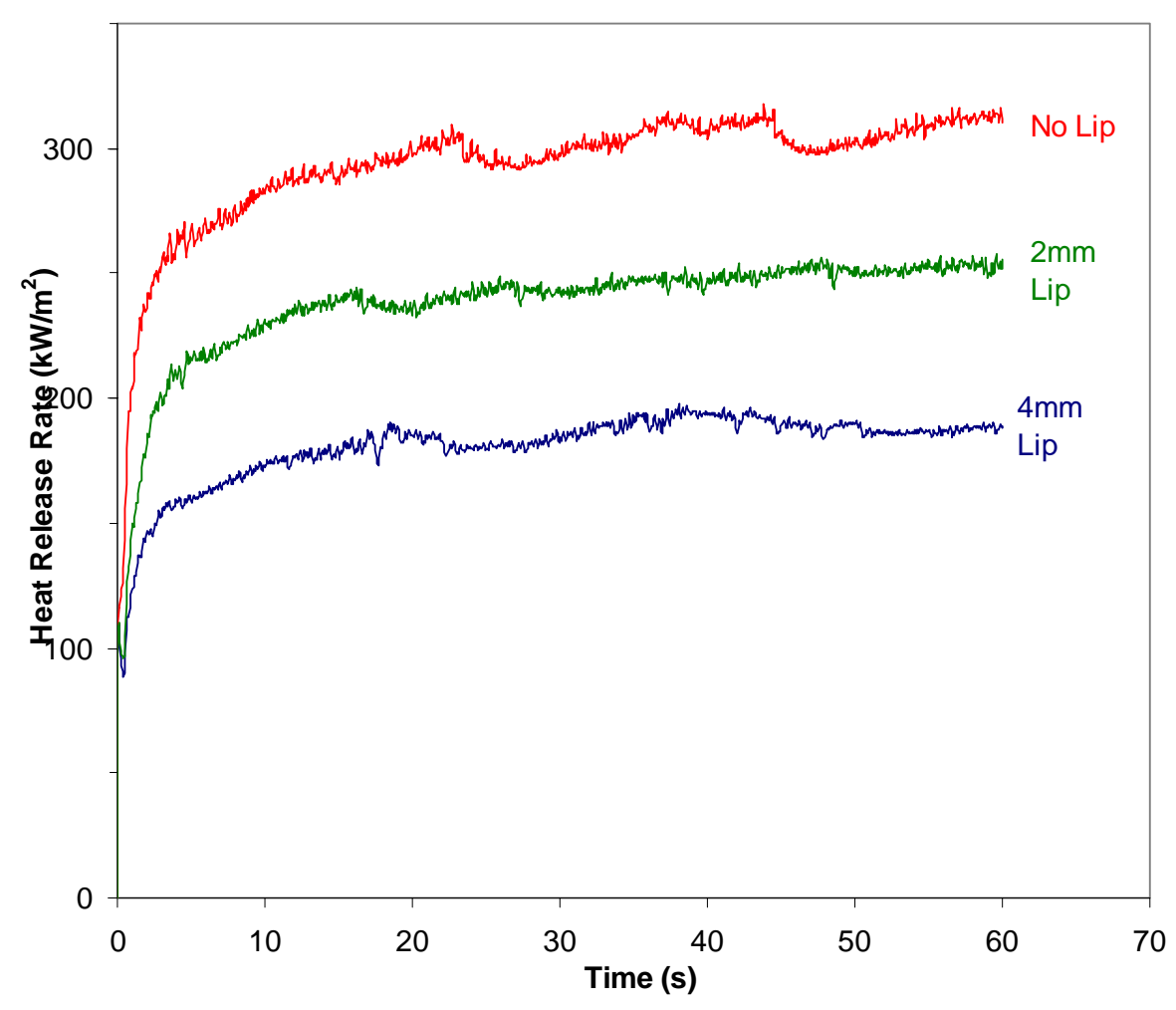

Figure 23 - Heat release rate of horizontal PMMA, $0 \mathrm{~kW} / \mathrm{m}^{2}$ imposed flux, with varying lip size at the top edge of the sample perimeter. 


\section{Exhaust Fan}

In the actual cone calorimeter experiments, a vent in the hood above the cone apparatus produces an exhaust velocity. The airflow through this vent is approximately $24 \mathrm{~L} / \mathrm{s}$ [5], which results in a velocity at the hood entrance of $15 \mathrm{~cm} / \mathrm{s}$. For the purposes of this simulation, a vent with this velocity was created along the entire upper physical domain boundary. As seen in Figure 24, the effect of this vent on the heat release rate was small.

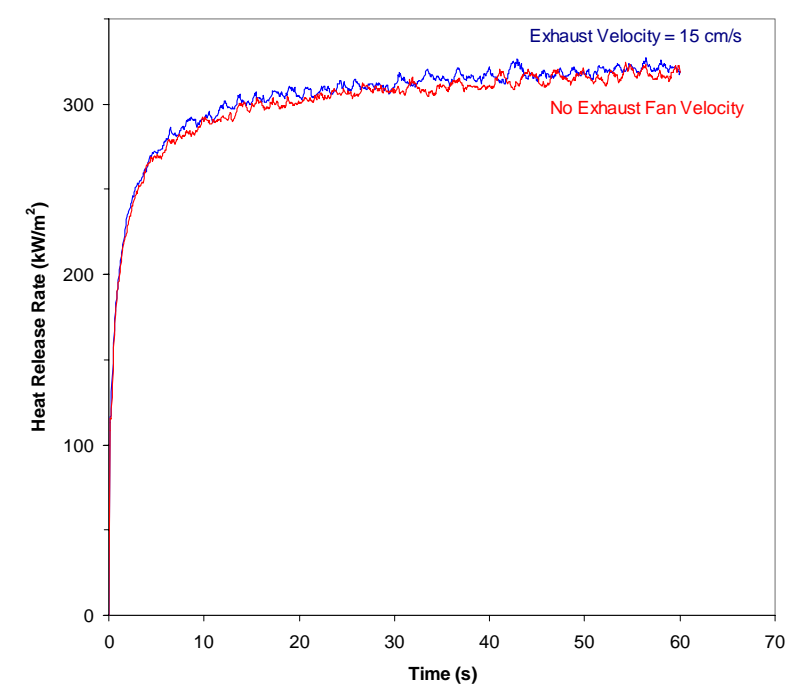

Figure 24 - Heat release rate of horizontal PMMA, $0 \mathrm{~kW} / \mathrm{m}^{2}$ imposed flux, with and without a $15 \mathrm{~cm} / \mathrm{s}$ imposed exit velocity on the top boundary of the calculation.

\section{External Heat Flux}

The major parameter varied in both the experiments and the calculations was the imposed radiant flux on the PMMA sample. In the experiments, this was achieved by adjusting the cone temperature until a calibrated Schmidt-Boelter heat flux gage indicated the desired heat flux (tests were run at $0,5,10,25,50$, and $75 \mathrm{~kW} / \mathrm{m}^{2}$ ). Similarly, in the calculations, the specified cone temperature was selected such that it provided the desired flux on the sample. The heat flux resulting from the cone temperature for the calculated vertical and horizontal cases, as well as the experimental horizontal case, is shown in Figure 25. The difference between the vertical and horizontal cases in FDS is probably due to the different view factors for the 2-D planar and 2-D axi-symmetric configurations of the calculations. Similarly, the $100 \mathrm{~K}$ difference between the required cone temperature in the experiment and in the calculation (for the horizontal case) may be due to differences in the geometry. 


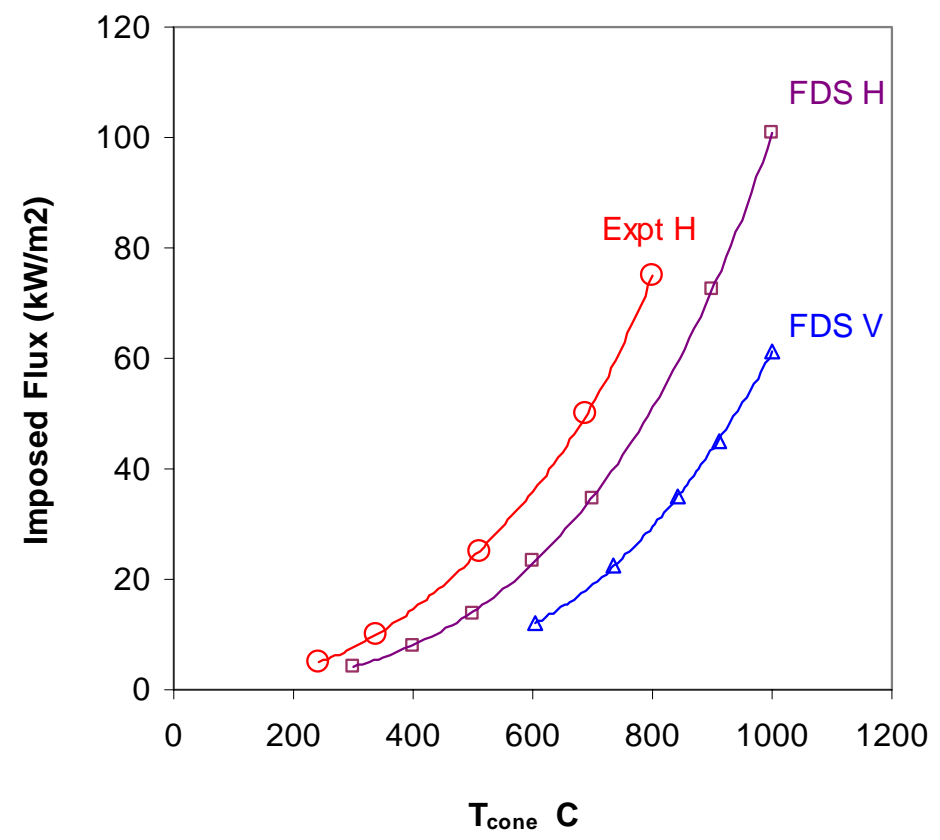

Figure 25 - Heater temperature required to produce a given incident flux on the PMMA sample in the FDS calculations for vertical $\mathrm{V}$ and horizontal $\mathrm{H}$ samples, and for the experiment with a horizontal sample.

Figure 26 shows the heat release rate from horizontal PMMA in the cone as a function of imposed heat flux from the cone; the experimental data are shown by the points, and the FDS predicted HRR is shown by the solid line. Similar results for the vertical PMMA are shown in Figure 27. A somewhat surprising result is that the horizontal and vertical cases provide essentially the same burning rate for the vertical and horizontal cases (c.f. the red points in Figure 26 and Figure 27), even down to $0 \mathrm{~kW} / \mathrm{m}^{2}$ imposed flux. FDS is able to predict the burning rate reasonably for both cases, although the increase in HRR with imposed flux (i.e., the slope of the line in the figures) is less in the calculations than in the experiment. The slope of this line can be modified by changing the heat of vaporization for PMMA in the FDS input file, as shown in Figure 28; however, this would make the agreement for the vertical case worse. For both orientations, the poorest agreement occurs for case of $0 \mathrm{~kW} / \mathrm{m}^{2}$ imposed flux. Reasons for this are described later in this manuscript. 


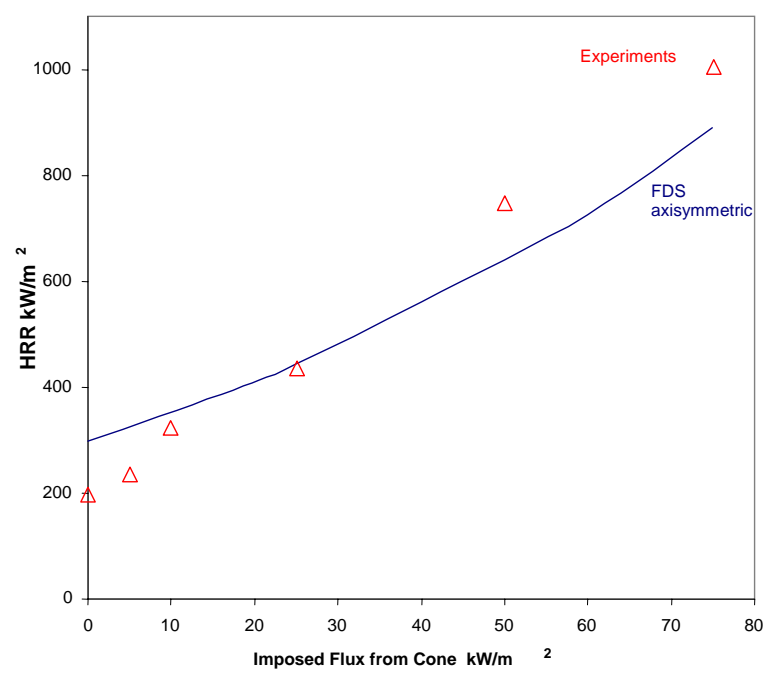

Figure 26 - Heat release rate as a function of imposed heat flux from the cone; horizontal PMMA sample.

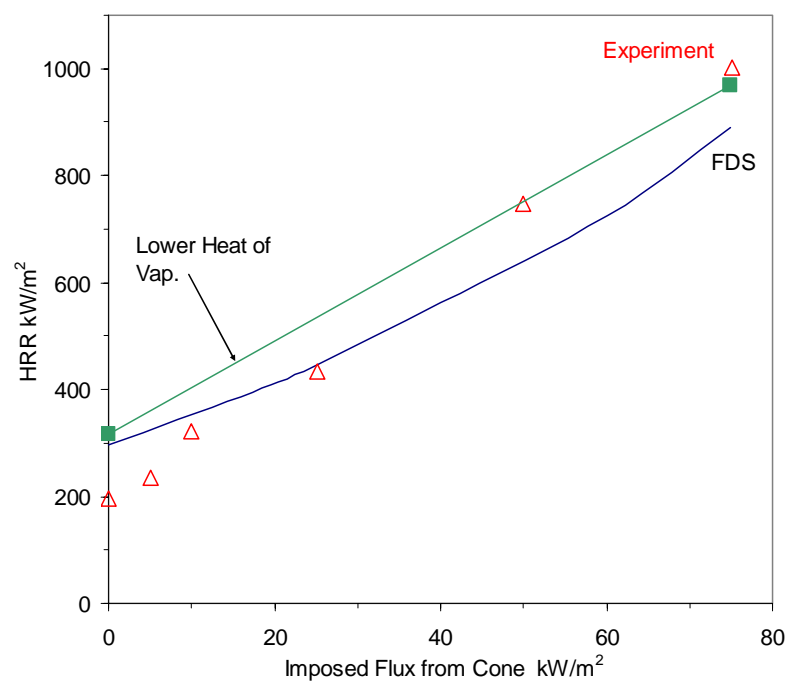

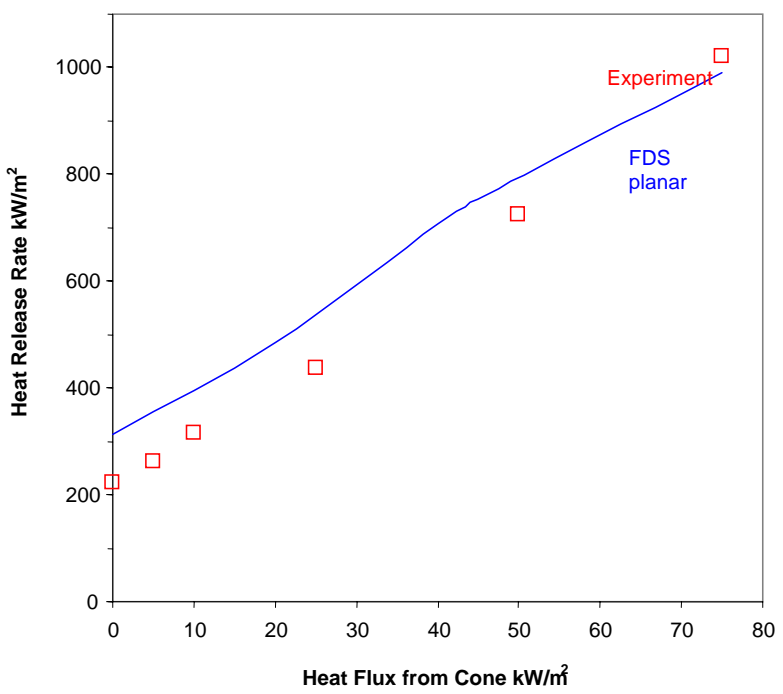

Figure 27 - Heat release rate as a function of imposed heat flux from the cone; vertical PMMA sample.

Figure 28 - Heat release rate of horizontal PMMA as a function of imposed heat flux with a $10 \%$ lower value for heat of vaporization of PMMA, plotted with the original results for heat release rate (horizontal PMMA, Figure 26). 


\section{Inverted Geometry Case}

Olson et al. [6] have recently described a system for producing low-strain flames over solid samples exposed to radiant fluxes that may be useful for predicting the behavior of flames in microgravity. The system basically uses an inverted cone calorimeter, and hence, their data provide us with an additional configuration (inverted) for testing FDS predictions of burning of PMMA in the cone. We ran simulations of their configuration corresponding to imposed radiant fluxes of $(0,10$, and 25$) \mathrm{kW} / \mathrm{m}^{2}$, for imposed vertical velocities of $(10,69$, and 200$) \mathrm{cm} / \mathrm{s}$, which correspond to strain rates of $(4.2,10$, and 27$) \mathrm{s}^{-1}$.

Figure 29, Figure 30, and Figure 31 present images of the FDS simulation of the cone and flame in the inverted configuration. The input files of our calculations were modified to include the flow-directing skirt around the sample and to provide an imposed flow up the center of the cone. In addition, the calculations were performed in the 2-D planar mode to avoid numerical instabilities that can occur near the $\mathrm{r}=0$ axis for calculations in axial symmetry. 

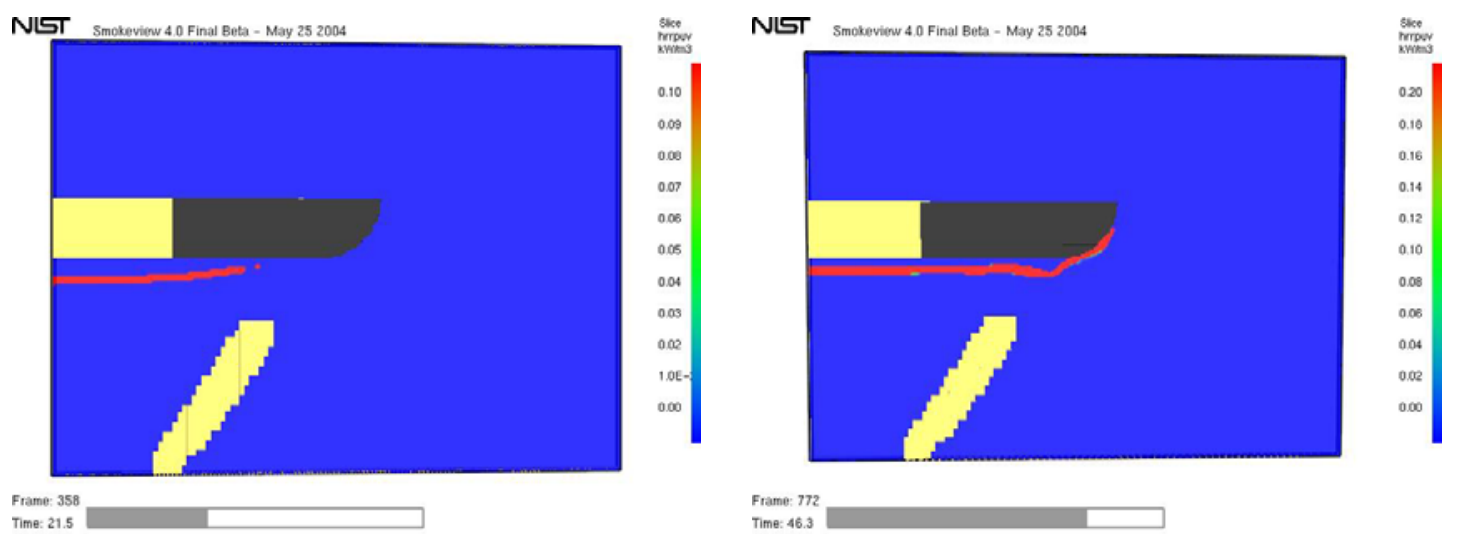

Figure 29 - Smokeview images of the PMMA sample, flame, and cone, $0 \mathrm{~kW} / \mathrm{m}^{2}$ imposed Flux (left, $10 \mathrm{~cm} / \mathrm{s}$; right, $69 \mathrm{~cm} / \mathrm{s}$ inlet velocity).
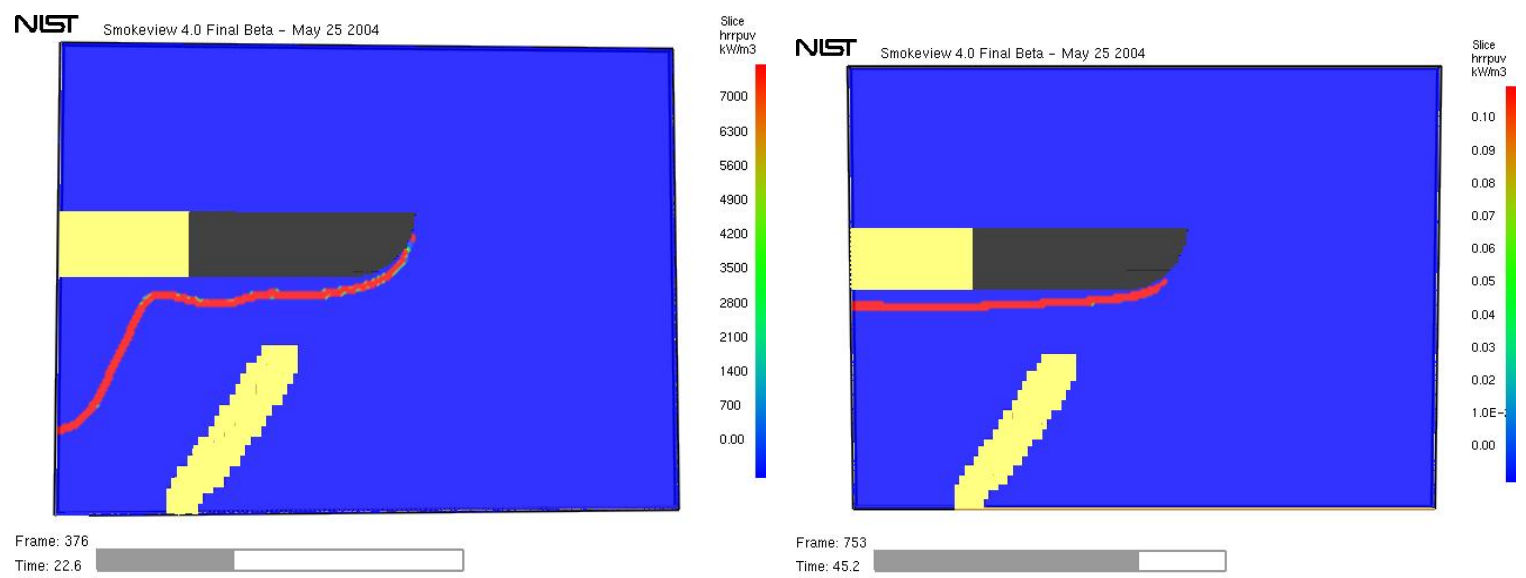

Figure 30 - Smokeview images of the PMMA sample, flame, and cone, $10 \mathrm{~kW} / \mathrm{m}^{2}$ imposed Flux (left, $10 \mathrm{~cm} / \mathrm{s}$; right, $69 \mathrm{~cm} / \mathrm{s}$ inlet velocity).
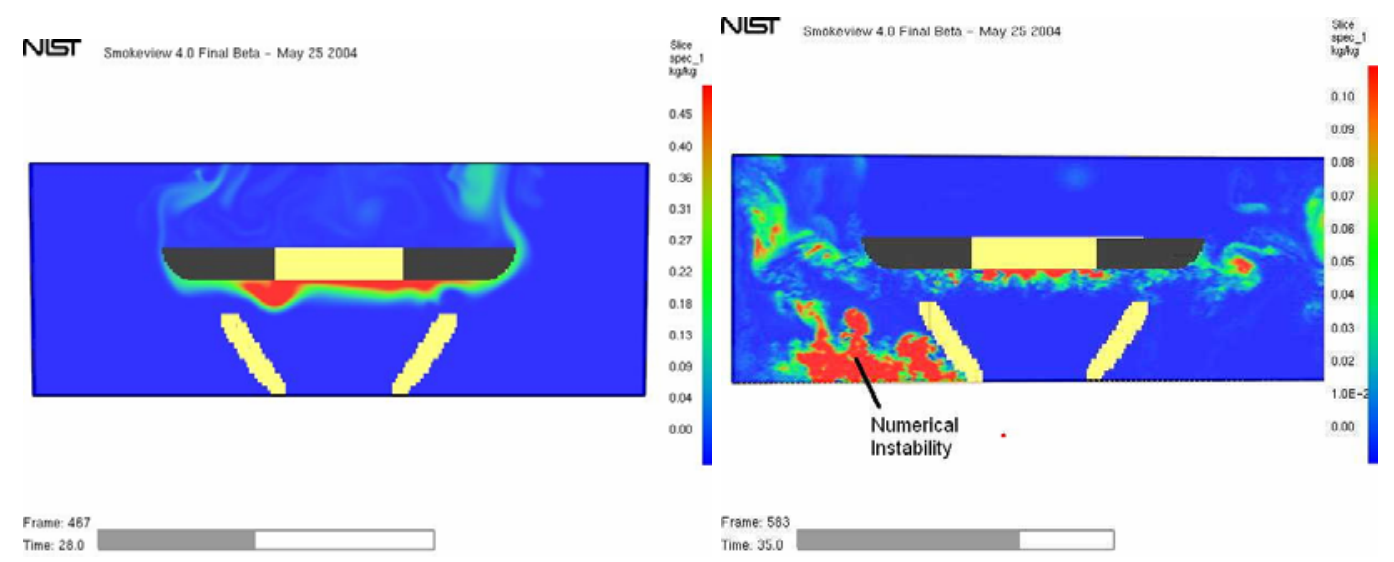

Figure 31 - Smokeview images of the PMMA sample, flame, and cone, $25 \mathrm{~kW} / \mathrm{m}^{2}$ imposed Flux (left, $10 \mathrm{~cm} / \mathrm{s}$; right, $200 \mathrm{~cm} / \mathrm{s}$ inlet velocity). 
Figure 32 shows the data of Olsen et al. together with FDS predictions. Unfortunately, most of the data are problematic. Except for the lowest strain $4.2 \mathrm{~s}^{-1}$, all of the calculations had numerical instabilities. Of the three low-strain calculations, those at ( 0 and 10$) \mathrm{kW} / \mathrm{m}^{2}$ imposed flux did not have numerical instabilities, but burned only for a few seconds and then extinguished, and hence were not in good agreement with the experiment. The other low-strain case (strain of $4.2 \mathrm{~s}^{-1}$ and an imposed flux of $25 \mathrm{~kW} / \mathrm{m}^{2}$ ) had good agreement with the experimental data. We are continuing the investigations to try to eliminate the numerical instabilities (which may be due to the large imposed axial flow velocities, $69 \mathrm{~cm} / \mathrm{s}$ and $200 \mathrm{~cm} / \mathrm{s}$, of those conditions).

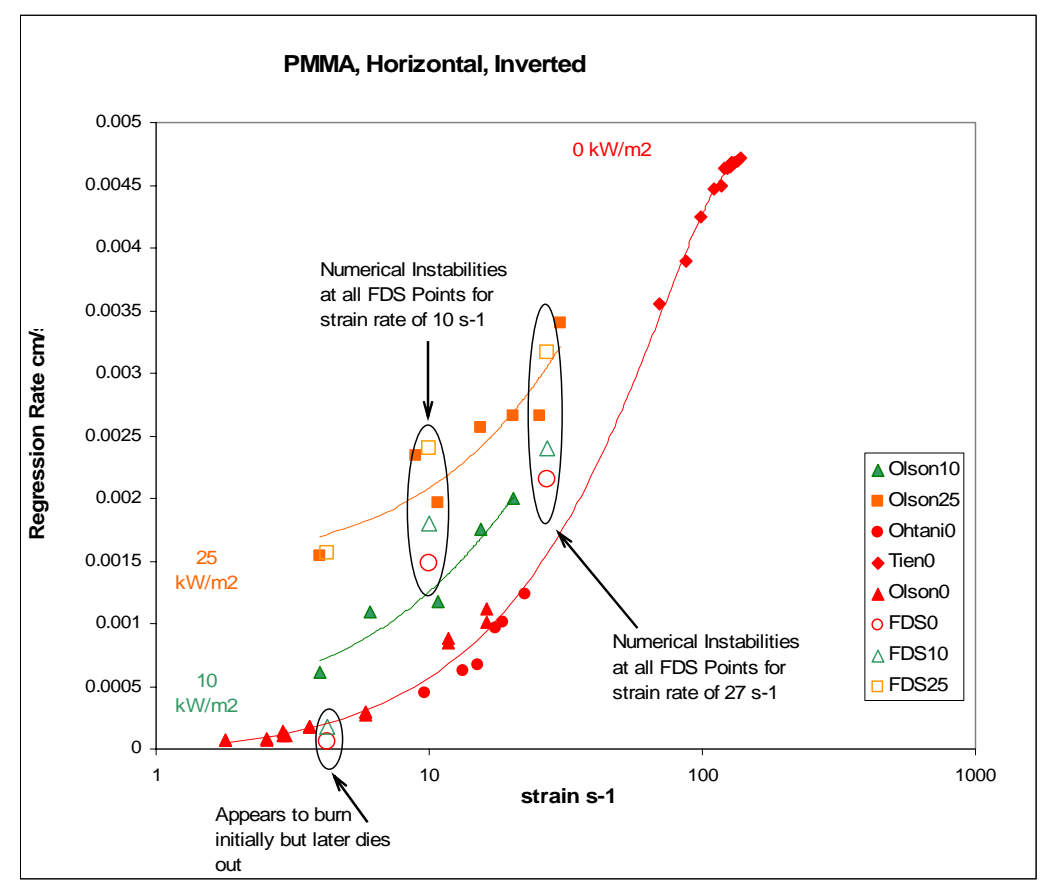

Figure 32 - Experimental data reported in [6] for clear PMMA burning at varying strains (4 s-1 to $27 \mathrm{~s}-1$ ) and with imposed radiant fluxes of $(0,10$, and 25$) \mathrm{kW} / \mathrm{m}^{2}$. Also shown are the results of FDS predictions.

\section{Surface Mass Loss Variation}

As described above, the non-uniform PMMA samples obtained at the conclusion of each burn provide the opportunity to estimate the burning rate variations over the surface of the samples. The surface topography of the PMMA samples was determined with an automated system, and select results are presented in Figure 33. As shown, the higher fluxes lead to greater fuel 

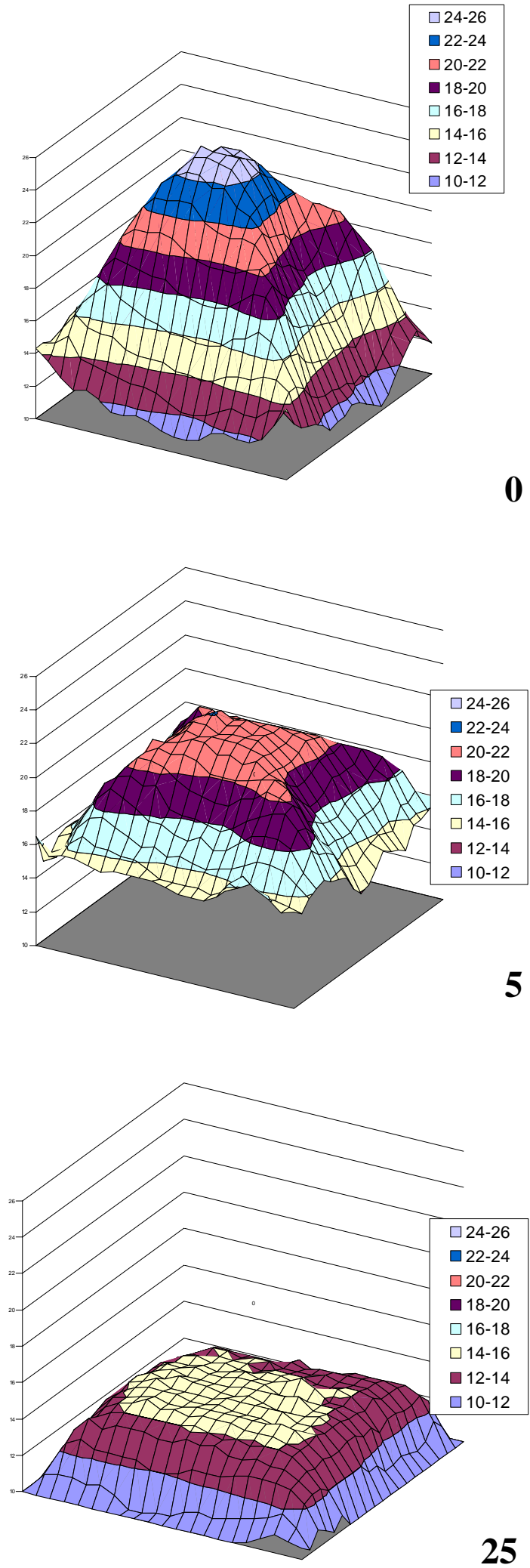
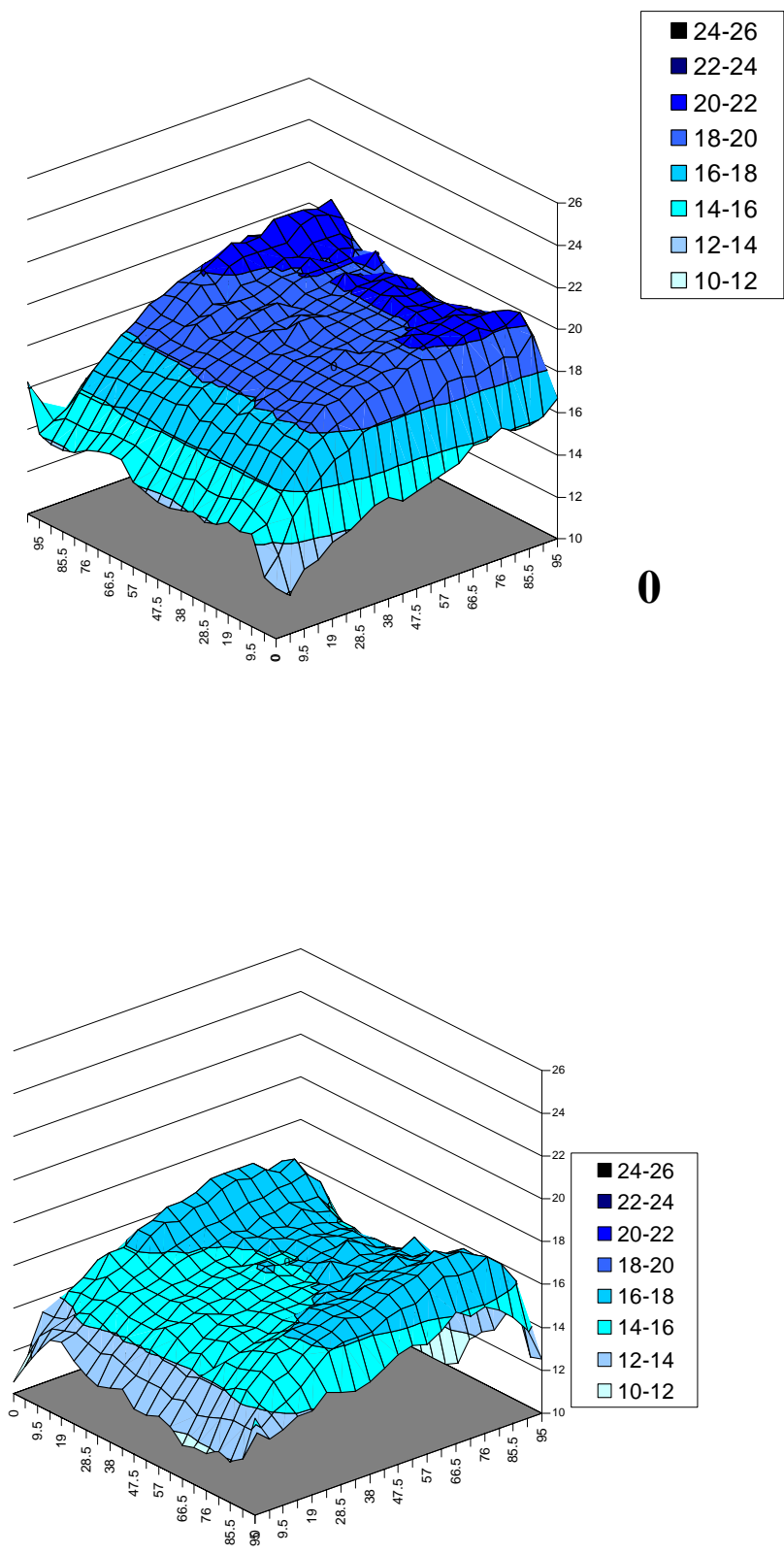

10

Figure 33 - Topography of remaining PMMA sample for horizontal (left) samples exposed to (0, 5 , and 25$) \mathrm{kW} / \mathrm{m}^{2}$ for $(1560,1053$, and 924$) \mathrm{s}$; and vertical samples at $(0$ and 10$) \mathrm{kW} / \mathrm{m}^{2}$ exposed for (825 and 813) s (note: the vertical axis goes from 10 to $25 \mathrm{~mm}$ ). 
consumption and a more uniform burning over the surface of the sample (the heat transfer at higher imposed flux is dominated by the thermal radiation from the cone, which is close to uniform). The vertical samples also burned more uniformly.

The FDS prediction and the experimental result for the surface topography $\left(0 \mathrm{~kW} / \mathrm{m}^{2}\right.$ imposed flux) are shown for the horizontal and vertical orientations in Figure 34 and Figure 35 . Since the numerical simulations for the 3-D calculations only ran for about $30 \mathrm{~s}$ or less, it was necessary to extrapolate these results for longer burn times to produce a sample topography similar to the experimental results (which had burn times of hundreds of seconds). To do this, we first determined the average burning rate over the surface of the sample for the last second of the calculation (15 s to $16 \mathrm{~s}$ for these cases, see Figure 15). Then, the burning time for the simulation was selected to give the same final mass of the experiments. With this integration time, the mass loss at each location on the surface was calculated based on the surface variation of the mass loss rate predicted by the 3-D calculation. This approach was used since: 1.) the calculation time for the 3-D simulation was very long, and we could not achieve the actual burning times in the time available for the calculations, and 2.) the FDS results for the average steady-state burning rate at $0 \mathrm{~kW} / \mathrm{m}^{2}$ flux was about $80 \%$ too high (see Figure 26 and Figure 27 at $0 \mathrm{~kW} / \mathrm{m}^{2}$ ), so using actual burning times would not give the proper total mass loss. While not quantitative, the approach used (selecting the burn time in the calculations to match the experimental mass loss) allows us to assess the overall ability of FDS to predict the distribution of surface erosion. As shown, the trends are correct, although for the calculation, the burning of the middle of the horizontal sample is too large and the gradient at the edges is too steep. For the vertical sample, the gradient of the mass loss rate at the edges is again much more gradual in the experiment as compared to the model. Nonetheless, there is a limit to the agreement between calculation and experiment in these cases since FDS does not allow changes to the sample geometry during burning. Hence, local changes to the heat transfer coefficient caused by changes to the shape of the sample, which would occur in the experiment but not in the calculation, may be responsible for the discrepancies observed here.

An alternative way to view these data is to make contour maps, for example, of the burning rate variation over the sample surface. The numerical and experimental results for the $0 \mathrm{~kW} / \mathrm{m}^{2}$ imposed flux for the horizontal and vertical orientations are shown in Figure 36 and Figure 37. It is interesting to note that for the horizontal case, there is very little burning in the center of the horizontal sample (in either the calculation or the experiment), as opposed to the vertical sample, for which burning occurs everywhere. In both orientations, the burning is much greater at the edges (although the calculations over-predict this effect). 

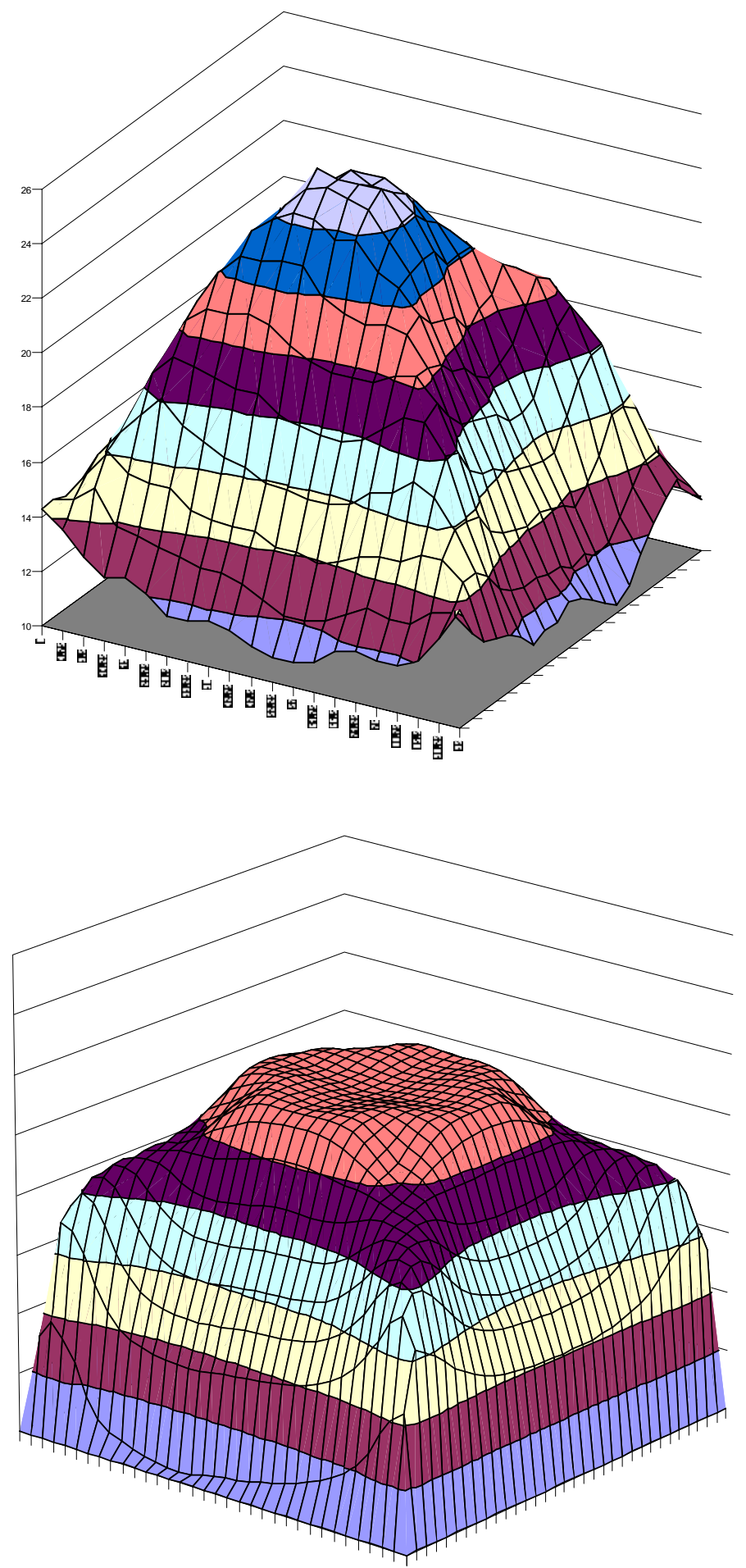

24-26

$\square$ 22-24

$\square$ 20-22

- 18-20

$\square$ 16-18

$\square$ 14-16

$\square$ 12-14

$\square$ 10-12 $\square$ 24-26

$\square$ 22-24

$\square$ 20-22

18-20

$\square$ 16-18

$\square$ 14-16

口 12-14

$\square$ 10-12

Figure 34 - Experimental (top) and 3-D FDS predicted surface topography of horizontal PMMA at $0 \mathrm{~kW} / \mathrm{m}^{2}$ imposed flux. The experiment ran for $1560 \mathrm{~s}$, and the simulation, $819 \mathrm{~s}$. 

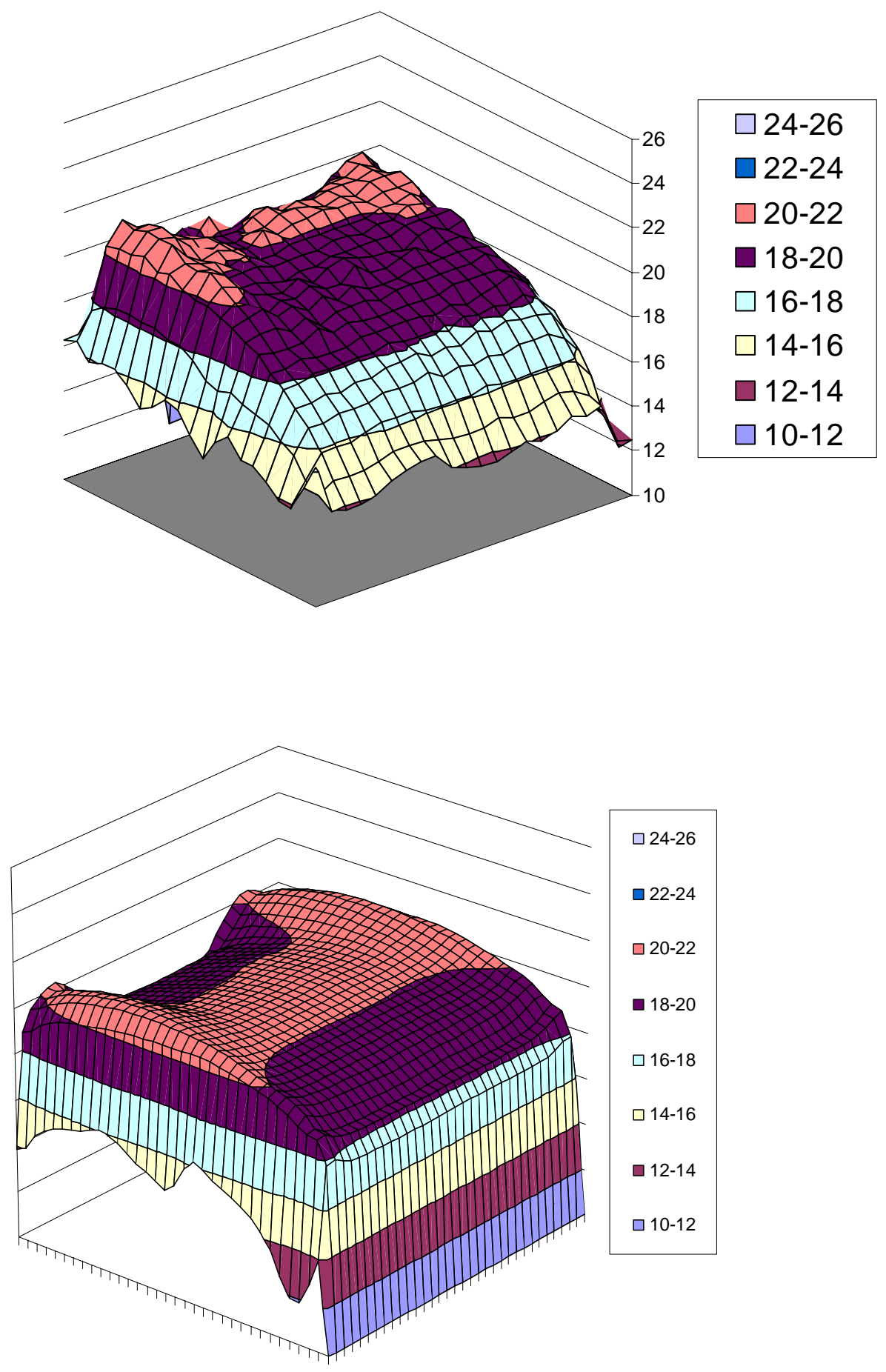

Figure 35 - Experimental (top) and 3-D FDS predicted surface topography of vertical PMMA at $0 \mathrm{~kW} / \mathrm{m}^{2}$ imposed flux. The experiment ran for $825 \mathrm{~s}$, and the simulation, $485 \mathrm{~s}$. 

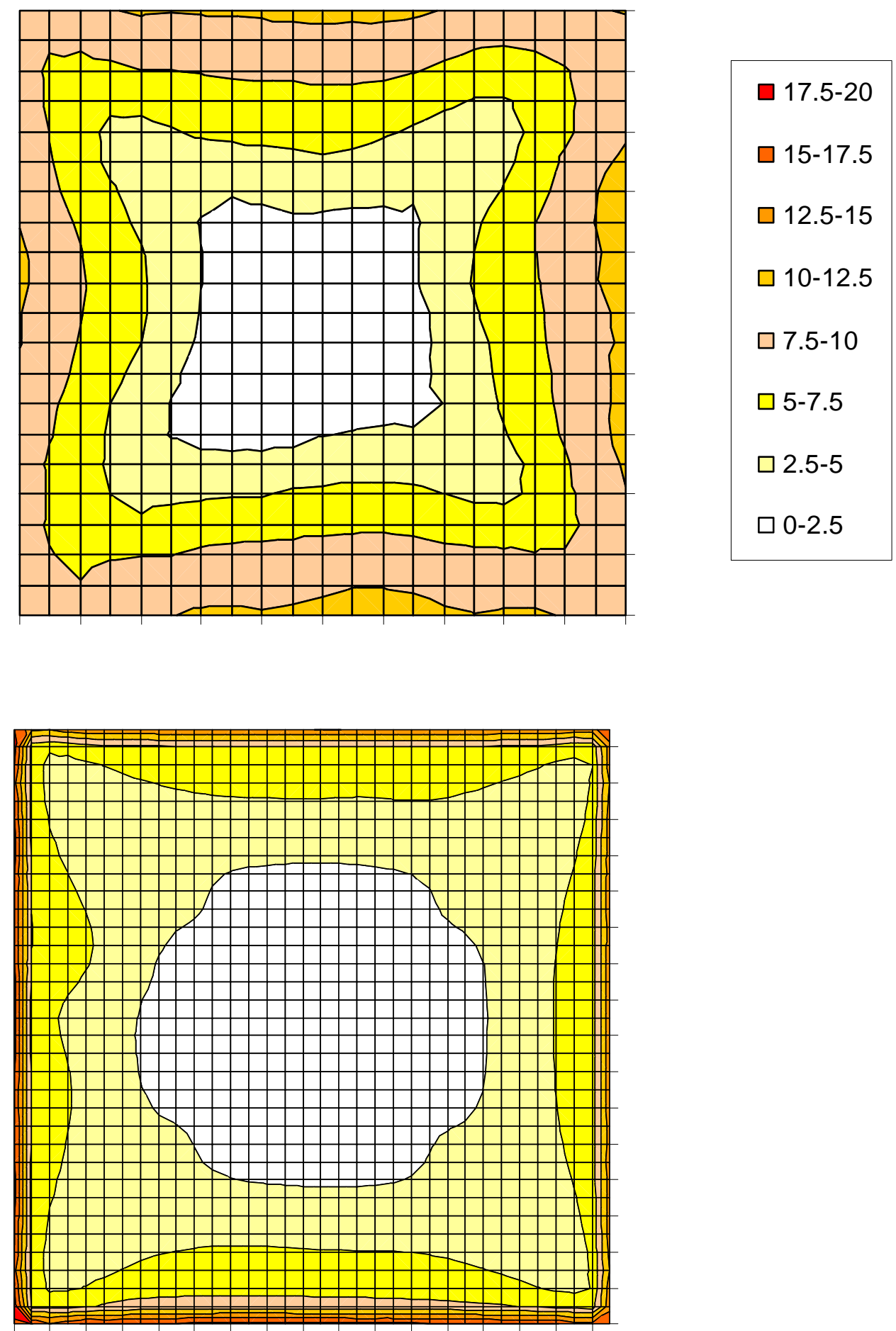

Figure 36 - Experimental (top) and FDS predicted (bottom) surface variation of mass loss rate (g/m $\left./ \mathrm{m}^{2} / \mathrm{s}\right)$ for horizontal burning PMMA with $0 \mathrm{~kW} / \mathrm{m}^{2}$ imposed flux (top view of $10 \mathrm{~cm} \times 10 \mathrm{~cm}$ sample). 


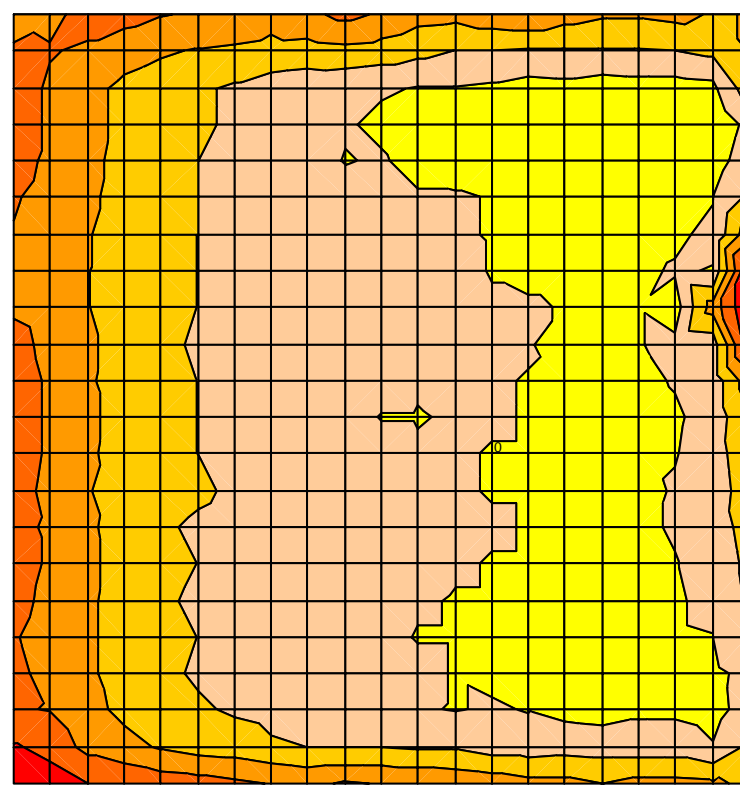

$\square$ 17.5-20.0

$\square 15.0-17.5$

$\square 12.5-15.0$

$\square 10.0-12.5$

$\square 7.5-10.0$

$\square 5.0-7.5$

$\square 2.5-5.0$

$\square 0.0-2.5$

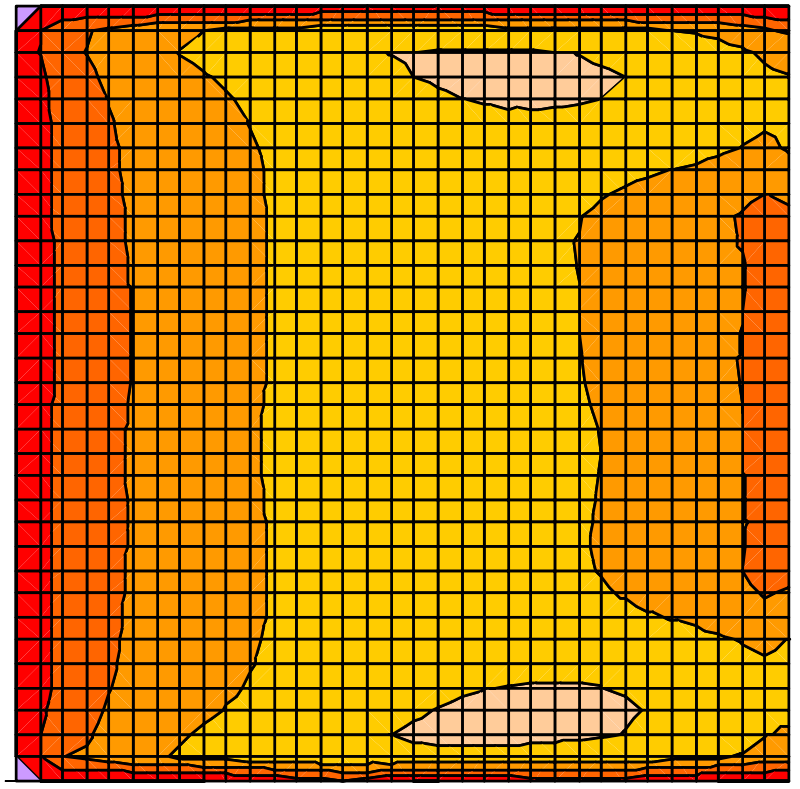

\begin{tabular}{|l|}
$\square 17.5-20.0$ \\
$\square 15.0-17.5$ \\
$\square 12.5-15.0$ \\
$\square 10.0-12.5$ \\
$\square 7.5-10.0$ \\
$\square 5.0-7.5$ \\
$\square 2.5-5.0$ \\
$\square 0.0-2.5$ \\
\hline
\end{tabular}

Figure 37 - Experimental (top) and FDS predicted (bottom) surface variation of mass loss rate $\left(\mathrm{g} / \mathrm{m}^{2} / \mathrm{s}\right)$ for vertical burning PMMA with $0 \mathrm{~kW} / \mathrm{m}^{2}$ imposed flux (top view of $10 \mathrm{~cm} \times 10 \mathrm{~cm}$ sample). 


\section{Conclusions}

FDS was used to simulate the burning of black PMMA samples in the cone calorimeter. Various parameters were found to have a large effect on either the experimental or calculated burning rates, and must be carefully controlled in the experiment or modeling. In the calculations, numerical parameters, physical, and experimental parameters were varied.

\section{Numerical Parameters:}

1. The domain size and grid resolution were both found to have a large effect, especially on the heat release rate in the gas phase.

2. The selection of DNS or LES mode did not make much difference for the present calculations (with $1 \mathrm{~mm}$ grid size).

3. The 2-D simulation (axisymmetric) was within a few percent of the 3-D calculation for horizontal samples, while the 2-D planar simulation for the vertical samples was about $7 \%$ lower than the 3-D simulation.

\section{Physical Parameters:}

1. Heat of vaporization, ignition temperature, and activation energy of the decomposition step all had a significant effect (about $10 \%$ ) on the burning rate over a range of variation of their values which may be observed in practice.

\section{Experimental Parameters:}

1. The presence or absence of the cone (with $0 \mathrm{~kW} / \mathrm{m}^{2}$ flux) above the horizontal sample was important in the experiment, but not important in the calculations.

2. The presence of the exhaust flow in the hood above the cone was not important in the calculations.

3. The presence of insulation on the back side of the sample was not important in either.

4. The presence of a lip on the sample edge was important in both the experiments and calculations, with a $4 \mathrm{~mm}$ lip changing the burning rate by almost a factor of two.

5. The variation in the average sample burning rate with changes to the imposed flux (over the range of $0 \mathrm{~kW} / \mathrm{m}^{2}$ to $75 \mathrm{~kW} / \mathrm{m}^{2}$ ) was predicted reasonably well by the simulations; however, as the imposed flux went down, the simulation overpredicted the average mass loss rate as compared to the experiment

6. For the $0 \mathrm{~kW} / \mathrm{m}^{2}$ imposed flux case, most of the heat flux from the flame to the sample occurs at the edges; however, the code over-predicts heat flux both in the center and at the edges.

The reasons for this over-prediction of the burning rate with no imposed flux are related to the fidelity with which the phenomena were set up in the numerical description. In the center, the heat flux is mainly by radiation, and the calculation was greatly simplified. Only gray-body radiation from an assumed soot volume fraction was included, and this may be in error. Gas-phase species were not included, and in particular, absorption of the IR radiation by the pyrolyzed but unburned MMA monomer is known to have an effect. Treatment of the 
edge condition may need to be improved, and the changes to the sample geometry during burning (not included in FDS) could affect the result. As the imposed heat flux from the cone increases, it dominates the heat flux to the sample, so these flame radiation and edge heat transfer effects are not so important (although possible absorption of the radiation by the MMA monomer, or its decomposition products, could still be important).

There exist significant problems with the inverted geometry for all values of the imposed flow and imposed radiation. Further work is needed to circumvent the numerical instabilities, and to determine the reasons for the non-burning behavior for the low-flow, low-flux cases.

In future work, it would be useful to look at the time dependence of all of the results generated in the present work, since only the steady-state results were analyzed in the present discussion. Futher, it would be of interest to study more complex solid fuels, for which the present capabilities of FDS for treating the solid phase would clearly need to be upgraded. Nonetheless, the present results provide a valuable foundation for understanding how the myriad experimental and numerical parameters which can be manipulated in the tests and the analyses affect the accuracy of the comparisons between calculations and experiment.

\section{Acknowledgements}

The authors are indebted to Dr. Richard Lyon of the FAA Technical Center for his initial calculations and experiments which motivated this work. Mr. Randy Shields conducted the experiments and made significant contributions to the experimental approaches. Mr. Ian Rafferty wrote the software and developed the PMMA surface topography analysis system. Helpful conversations with Dr. William (Ruddy) Mell concerning PMMA modeling are gratefully acknowledged.

\section{References}

1. McGrattan, K. B. and Forney, G. P., Fire Dynamics Simulator (Version 4): User's Guide , NISTSP 1019, 2004.

2. McGrattan, K. B., Fire Dynamics Simulator (Version 4) Technical Reference Guide., NISTSP 1018, 2004.

3. Forney, G. P. and McGrattan, K. B., User's Guide for Smokeview Version 4 - A Tool for Visualizing Fire Dynamics Simulation Data, NISTSP 1017, 2004.

4. Kashiwagi, T., Proc. Combust. Inst. 25:1423 (1994).

5. Twilley, W. H. and Babrauskas, V., User's Guide for the Cone Calorimeter, SP-745, 1988.

6. Olson, S.L., Beeson, H.D., Hass, J.P., and Baas, J.S., Proc. Combust. Inst. 30:to appear (2004).

7. Tewarson, A., Experimental Evaluation of Flammability Parameters of Polymeric Materials, FMRC J.I. 1A6R1.RC, 1979.

8. Babrauskas, V., Twilley, W.H., and P arker, W.J., Fire and Materials 17:51 (1993-1994). 
Figure 7

From: ...Excel Files $\backslash$ PMMA_Horizontal+vertical.xls

Sheet: Composite HRR

Figure 18

From: 